\title{
Iron Complexes of Octaphenyltetraazaporphine
}

\author{
Pavel A. Stuzhin \\ Department of Organic Chemistry, Ivanovo State University of Chemical Technology, RF-153000, Ivanovo, Russia \\ E-mail: stuzhin@isuct.ru
}

\begin{abstract}
This review is dedicated to my teacher Professor B. D. Berezin on occasion of his $80^{\text {th }}$ birthday and considers the results obtained during investigation of iron octaphenyltetraazaporphyrin complexes (FeOPTAP), which was initiated by his suggestion. Although synthesis and some catalytic properties of FeOPTAP have being mentioned already in the pioneering works of Linstead and Cook [J. Chem. Soc. 1937, 929-933; 1938, 1761-1780, 1845-1847] this species was not characterised and its coordination chemistry remained unknown. We have shown that template condensation of diphenylfumarodinitrile with $\mathrm{Fe}(\mathrm{CO})_{5}$ in boiling 1-bromonaphthalene affords the crude bromoiron(III) complex [(Br)FeOPTAP] which can be easily converted in a number of various coordination forms with different oxidation and spin state of iron. This complex and other five-coordinated acido complexes [(X)FeOPTAP] (X-anion of a strong inorganic or carboxylic acid) contain iron(III) in the intermediate spin state $S=3 / 2$. Treatment of [ $(X) F e O P T A P]$ with $N$-bases L or anionic nucleophiles $A^{-}(e . g$. $\mathrm{OH}, \mathrm{OR}, \mathrm{CN}^{-}, \mathrm{SCN}^{-}, \mathrm{OCN}^{-}, \mathrm{N}_{3}^{-}$) in non-coordinating solvents with low dielectric constant (benzene or CHCl) leads first to mixed six-coordinated complexes $([(L)(X) F e O P T A P]$ or $[(A)(X) F e O P T A P]-)$ and then to cationic or anionic low-spin $(S=1 / 2)$ iron(III) species $\left(\left[(L)_{2} \mathrm{FeOPTAP}\right]^{+}\right.$or $\left.\left[(A)_{2} \mathrm{FeOPTAP}\right]^{-}\right)$. In solvents with higher dielectric constant and/or donor properties (acetone, dimethylsulfoxide, etc) iron(III) is reduced to iron(II) with formation of diamagnetic six-coordinate iron(II) complexes $\left[(\mathrm{L})_{2} \mathrm{FeOPTAP}\right]$ or $\left[(\mathrm{A})_{2} \mathrm{FeOPTAP}\right]^{2}$. Heating of $\left[(\mathrm{L})_{2} \mathrm{FeOPTAP}\right]$ in vacuum affords four-coordinated intermediate spin $(S=1)$ iron(II) complex $\left[(L){ }_{2} F e O P T A P\right]$ which is easily oxidised in air to the binuclear $\mu$-oxodiiron(III) complex $\mu-\mathrm{O}[\mathrm{FeOPTAP}]_{2}$. This species is also easily obtained from $[(X) \mathrm{FeOPTAP}]$ during chromatography on neutral or basic $\mathrm{Al}_{2} \mathrm{O}_{3}$. Treatment of $\mu-\mathrm{O}[\mathrm{FeOPTAP}]_{2}$ with acid $\mathrm{HX}$ leads to $[(X) \mathrm{FeOPTAP}]$ and with $\mathrm{N}$-base L to $\mu$-O $[(L) \mathrm{FeOPTAP}]_{2}$ which is then reduced to $\left[(L)_{2}\right.$ FeOPTAP]. $\mu$-Nidrido diiron $(I I I / 2)$ complex $\mu$-N $[\mathrm{FeOPTAP}]_{2}$ which is formed from the azide derivative $\left[\left(\mathrm{N}_{3}\right) \mathrm{FeOPTAP}\right]$ upon refluxing in benzene can form an adduct with $\mathrm{N}$-bases and bind $\mathrm{O}_{2}$. Reactive nitridocomplex $[N \equiv F e O P T A P]$ containing most likely iron $(V)$ was shown to be the key intermediate in the formation of $\mu$-nitrido complexes and heteroleptic and heterometallic $\mu$-nitrido species $\mu$ - $N(F e O P T A P)(F e T P P)$ and $[\mu-N(F e O P T A P)$ $(\mathrm{MnOPTAP})]$ were also described. Treatment of $[(X) \mathrm{FeOPTAP}]$ with $\mathrm{CI}_{4}$ under reductive conditions or with $\mathrm{CHCl}_{3}$ in alkali media leads to the $\mu$-carbido complex $\mu$-C $[\mathrm{FeOPTAP}]_{2}$. Results of spectral study (UV-vis, IR, ${ }^{1} H \mathrm{NMR}$, ESR and Mössbauer), investigation of redox and ligand binding/exchange reactions are also reviewed.
\end{abstract}

Keywords: Octaphenyl substituted tetraazaporphyrins, iron complexes, structure, oxidation and spin-states, ligand exchange, UVvis, ${ }^{1} \mathrm{H}$ NMR and Mössbauer spectroscopy, magnetic susceptibility.

Стужин Павел Анатольевич, родился в 1960 2. в Иваново. В 1977 году поступил в Ивановский химико-технологический институт (ИХТИ, в наст. время ИГХТУ) и с 1978 года начал заниматься исследованием азапорфиринов под руководством профессоров Б.Д. Берёзина и О.Г. Хелевиной. После окончания ИХТИ в 1982 году поступил в аспирантуру на кафедру органической химии и в 1985 году защцттил диссертацию кандидата химических наук на тему «Кислотно-основные и донорно-акиепторные свойства тетраазапорфина, его функичинальных производных и их комплексных соединений». Стажировался у профессоров Л. Латос-Гражинского (Вроч-

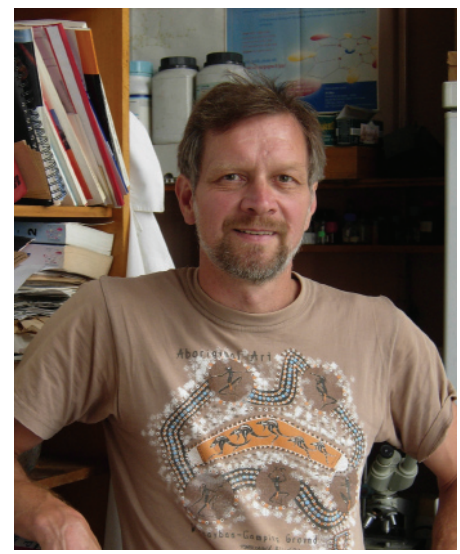

Professor Pavel Anatolievich Stuzhin was born in Ivanovo in 1960. In 1982 he graduated from Ivanovo Institute of Chemical Technology (IICT, presently State University, ISUCT) where since 1978 started research of meso-azasubstituted porphyrins under the supervision of Professor B. D. Berezin and O.G. Khelevina. After postgraduate courses at the Department of Organic Chemistry in 1985 he received the Degree "Candidate of Chemical Sciences" (PhD) presenting the dissertation "Acid-base and donor-acceptor properties of tetraazaporphine, its functional derivatives and their complexes". He was postdoctoral fellow by Prof. L. Latos-Grazynski at the University of Wroclaw (Poland, 1987), by лавский Университет, Польша, 1987), Х. Хомборга (Кильский Университет, Германия, 1992-94) и К. Эрколани (Римский Университет, Италия, 1995). В 2004 году защчтти диссертацчию доктора химических наук на тему "Синтез, строение и физико-химические свойства азапорфиринов и порфиразинов». C 1986 года преподает на кафедре органической химии Ивановского государственного химико-технологического университета (с 2004 года-профессор). Занимается исследованием мезо-азазамещённых порфиринов и порфиразинов.
Prof. H. Homborg at the University of Kiel (Germany, 1992-1994) and research associate by Prof. C. Ercolani at the Rome University "La Sapienza» (Italy, 1995). In 2004 he defended the dissertation "Synthesis, structure and physical-chemical properties of azaporphyrins and porphyrazines" and received the Degree "Doctor of Chemical Sciences'. Since 1985 he held Faculty position in Department of Organic Chemistry at ISUCT (professor since 2004). His research interests are connected with study of meso-azasubstituted porphyrins and porphyrazines. 


\title{
Комплексы железа с октафенилтетраазапорфином
}

\author{
П. А. Стужин
}

Ивановский государственный химико-технологический университет, 153000 Иваново, Россия

E-mail: stuzhin@isuct.ru

\begin{abstract}
В обзоре представлены результаты исследования комплексов железа с октафенилтетраазапорфином, которые были инициированы моим учителем профессором Борисом Дмитриевичем Берёзиныл. Показано многообразие координационных форм, содержащих железо в различном окислительном и спиновом состояниях, образование и устойчивость которых определяется экстралигандами. Тетракоординационный комплекс железа(II), являясь промежуточно-спиновым $(S=1)$, легко окисляется, а устойчивой формой комплексов железа(II) являются гексакоординационные диамагнитные низкоспиновые комплексы [(L) ${ }_{2} \mathrm{FeOPTAP]} \mathrm{и}$ $\left[(A){ }_{2} \mathrm{FeOPTAP}\right]^{2-}\left(L-N\right.$-основание, $A^{-}$- анион псевдогалогенида). Пентакоординационные комплексы железа(III) [(X)FеOPTAP] ( $X^{-}$- анион сильной минеральной или карбоновой кислоты) являются промежуточно-спиновыми $(S=3 / 2)$, а гексакоординационные катионные $\left[(L)_{2} \text { FeOPTAP }\right]^{+}$, анионные $\left[(A)_{2}\right.$ FeOPTAP] и смешанные $[(L)(X)$ FеОРТAP] или [(A)(X)FеОРТАР- - низкоспиновыми $(S=1 / 2)$. Были получены и изучены также биядерные

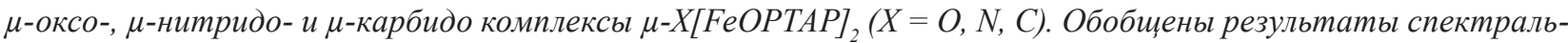
ных исследований (электронная спектроскопия поглощения, ИК, ${ }^{1}$ Н ЯМР, ЭПР и Мёссбауэровская спектроскопия), изучения электрохимических свойств и реакций связывания и обмена экстралигандов.
\end{abstract}

Ключевые слова: Октафенилзамещённые тетраазапорфирины, комплексы железа, строение, спиновое состояние, обмен лигандов, электронная, ${ }^{1} \mathrm{H}$ ЯМР и Мёссбауэровская спектроскопия, магнитная восприимчивость.

\section{Немного истории}

Когда в 1977 году школьное увлечение химией привело меня в Ивановский химико-технологический институт, передо мной не стояло вопроса «Кем быть?». Воодушевлённый успехами, достигнутыми на химических Олимпиадах школьников, я хотел стать ученымхимиком. Студенту-первокурснику не просто было определиться с тем к кому пойти учиться. Моя школьная учительница химии Веселова Муза Васильевна посоветовала мне идти на кафедру органической химии к профессору Берёзину Борису Дмитриевичу, который изучает уникальные вещества живой природы - хлорофилл, гем крови. Очень хорошо помню, как я ждал у кабинета Бориса Дмитриевича, как зашел к нему когда он освободился, и, набравшись смелости, сказал, что я хочу изучать порфирины. Борис Дмитриевич очень приветливо встретил меня и определил на выучку к Ольге Григорьевне Хелевиной, которая недавно начала заниматься новой малоисследованной тематикой тетраазазамещённых порфиринов.

Первой моей научной книгой и учебником стала только что вышедшая монография Б. Д. Берёзина «Координационные соединения порфиринов и фталоцианинов». ${ }^{[1]}$ Для меня было очень интересно получить на основе Линстедовской методики ${ }^{[2]}$ октафенилтетраазапорфин ( $\left.\mathrm{H}_{2} \mathrm{OPTAP}\right)$ и первой моей научной задачей было исследование реакции его комплексообразования с ацетатами переходных металлов $\left(\mathrm{Cu}^{\mathrm{II}}, \mathrm{Zn}^{\mathrm{II}}, \mathrm{Ni}^{\mathrm{II}}, \mathrm{Co}^{\mathrm{II}}\right.$, $\mathrm{Mn}^{\mathrm{II}}$ ) в пиридине. Это стало темой моей дипломной работы, а затем и первой публикации. ${ }^{[3]}$ Обнаруженный нулевой порядок реакции по соли металла не согласовывался с хорошо исследованным Борисом Дмитриевичем бимолекулярным механизмом комплексообразования собственно порфиринов. Поэтому наши результаты он сначала воспринимал с некоторым недоверием и мы с Ольгой Григорьевной тщательно проверяли и перепроверяли все данные прежде, чем представить их для обсуждения. Результатом дискуссий стал вывод о возможности реализации в случае тетраазапорфиринов особого мономолекулярного механизма комплексообразования. Во время обучения в аспирантуре Борис Дмитриевич включил в круг исследования менее доступные тетраазапорфирины - незамещённый $\mathrm{H}_{2}$ ТАР и алкилзамещённый $\mathrm{H}_{2}$ ТТМТАР, которые также были получены по Линстедовским методикам, ${ }^{[4,5]}$ и поставил задачу всесторонней характеристики их координационных и кислотно-основных свойств.

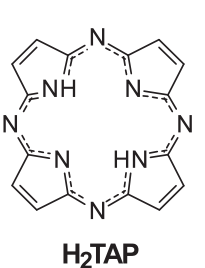

$\mathrm{H}_{2}$ TAP

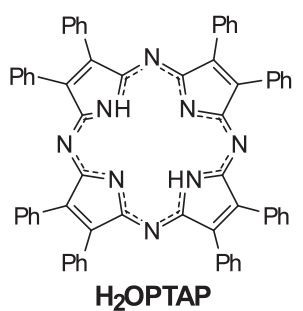

$\mathrm{H}_{2}$ OPTAP

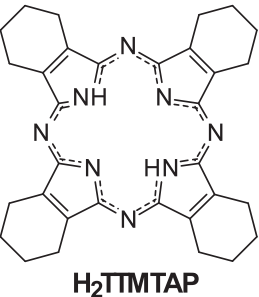

$\mathrm{H}_{2}$ TTMTAP
Исследования механизма реакций комплексообразования порфириновых лигандов с солями переходных металлов и сольвопротолитической диссоциации металлокомплексов в кислых средах в то время активно развивались под руководством Бориса Дмитриевича. Нам впервые удалось изучить реакцию комплексообразования тетраазапорфина не только с переходными металлами, ${ }^{[6]}$ но и с солями магния, ${ }^{[7]}$ а также наблюдать образование необычной пиридиниевой соли октафенилтетраазапорфина. ${ }^{[3]}$ Диссоциация комплексов тетраазапорфиринов с переходными металлами проходила 
лишь в горячей концентрированной серной кислоте и сопровождалась деструкцией макроцикла, поэтому эти исследования я проводил без особого энтузиазма - не хотелось разрушать прекрасные тетраазапорфирины. Было очень радостно, когда комплексы палладия и кобальта обнаружили необычно высокую устойчивость и не поддавались серной кислоте. ${ }^{[8]}$ Гораздо интереснее оказалось изучать сложные обратимые процессы протонирования тетраазапорфина и его комплексов с использованием спектрофотометрического титрования в средах с известной функцией кислотности Гаммета (например, смеси серной кислоты с уксусной). Оказалось, что в отличие от собственно порфиринов в тетраазапорфиринах в кислотно-основное взаимодействие вступают не внутренние пирролениновые, а внешние мезо-атомы азота, причем даже в среде $100 \%$-ной серной кислоты наблюдается спектральное проявление не более чем двух кислотных форм. Эти исследования оказались особенно интересными и важными на фоне развернувшейся в те годы жаркой дискуссии Бориса Дмитриевича, сделавшего на основе данных метода растворимости вывод об однократном протонировании комплексов фталоцианинов в серной кислоте, ${ }^{[1]}$ с оспаривавшими этот вывод отечественными исследователями (О.Л. Калия и Е.А. Лукьянец, ${ }^{[9]}$ А.С. Акопов $\left.{ }^{[10]}\right)$, которые, также как и ряд зарубежных учёных, ${ }^{[11,12]}$ наблюдали для растворов комплексов фталоцианинов в кислых средах последовательное образование четырёх спектрально различимых кислотных форм. Оказалось, что процесс протонирования таких слабых многоцентровых оснований, как тетраазапорфирины и фталоцианины, является сложным многостадийным процессом, характеризующимся различной степенью завершенности процесса переноса протона в зависимости от ионизирующей способности среды и «глубины протонирования» соседних основных центров. ${ }^{[13]}$

После защиты в 1985 году кандидатской диссертации «Кислотно-основные и донорно-акцепторные свойства тетраазапорфина, его функциональных производных и их комплексных соединений» ${ }^{[14]}$ Борис Дмитриевич вызвал меня и сказал, что пришла пора заняться разработкой собственной самостоятельной тематики и посоветовал начать исследования в области координационной химии комплексов железа с азапорфиринами. Я сразу же загорелся этой идеей, ведь среди координационных соединений, образуемых лигандами порфиринового типа, комплексы железа занимают особое место. Природные Fе-порфирины играют огромную роль в биологических системах, выполняя функцию переноса кислорода (гем крови), входя в состав важнейших металл-содержащих ферментов (пероксидаза, катализа, цитохромы), а синтетические Fe-порфирины и их структурные аналоги - Fe-фталоцианины проявляют каталитические и другие практически ценные свойства.

В то время координационная химия и физикохимические свойства природных и синтетических Feпорфиринов были достаточно хорошо изучены в работах зарубежных авторов и результаты обобщены в трехтомной коллективной монографии «Железопорфирины», вышедшей под редакцией Левера и Грея,, ${ }^{[15]}$ а также в обзоре Шейдта и Рида. ${ }^{[16]}$ В координационной химии $\mathrm{Fe}$-фталоцианинов ясности было меньше и наблюдалось противоречие между выводами отечественных авторов (Калия и Лукьянец), ${ }^{[17]}$ которые считали, что в комплексах с фталоцианинами, в отличие от комплексов с порфиринами, атом железа имеет исключительно степень окисления +2 , и результатами зарубежных учёных (Эрколани ${ }^{[18]}$ и Хомборг $\left.{ }^{[19]}\right)$, в работах которых были охарактеризованы комплексы фталоцианинов как с $\mathrm{Fe}^{\mathrm{II}}$, так и с $\mathrm{Fe}^{\mathrm{III}}$, и даже с $\mathrm{Fe}^{\mathrm{IV}}{ }^{[20]}$ Внести ясность в этот вопрос могли исследования комплексов железа с тетраазапорфиринами, которые по своей структуре являются мостиковым звеном между порфиринами и фталоцианинами. Борис Дмитриевич, обладая огромным научным кругозором и чутьём выдающегося учёного, нацелил меня на самую актуальную тематику. Я очень благодарен ему за это предложение и за то что в дальнейшем он всячески поддерживал исследования

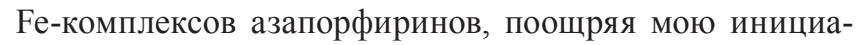
тиву и практически полную самостоятельность, а также предоставляя возможность руководства аспирантами. В настоящем обзоре представлены основные результаты, полученные мною ${ }^{[21]}$ и нашими аспирантами - Ириной Мигаловой (Тюлянкиной), ${ }^{[22]}$ Махмудом Хамдушем ${ }^{[23]}$ и Ольгой Мальчугиной (Кузьминой), ${ }^{[24]}$ а также Татьяной Виноградовой (Громовой) ${ }^{[25]}$ и Сергеем Вагиным, ${ }^{[26]}$ при исследовании различных координационных форм комплексов октафенилтетраазапорфирина с железом.

\section{Синтез и координационная химия комплексов железа с октафенилтетраазапорфином}

Впервые комплексы железа с тетраазазамещёнными порфиринами упоминали ещё Фишер ${ }^{[27]}$ и Линстед ${ }^{[2]}$ в своих классических работах, опубликованных в 1937 году, однако эти соединения остались не охарактеризованными. Описанный Линстедом комплекс железа с октафенилтетраазапорфином, для которого Кук в 1938 году показал наличие каталитической активности,, ${ }^{[28]}$ мы выбрали в качестве первого наиболее доступного объекта для исследования. Удивительно, что в отличие

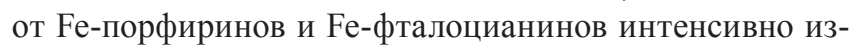
учавшихся с середины 1960-х годов, координационная химия Fe-тетраазапорфиринов до начала наших работ в 1986 году оставалась неисследованной.

\section{Синтез и многообразие координациинных форм}

Для синтеза $\mathrm{Fe}$-октафенилтетраазапорфина мы использовали темплатную конденсацию дифенилфумародинитрила (ДФФН, Схема 1) с пентакарбонилом железа в кипящем 1-бромнафталине и в результате получили продукт красно-коричневого цвета. При растворении в пиридине образовывался сиреневый раствор с красной флуоресценцией, электронный спектр поглощения (ЭСП) которого был типичен для комплексов тетраазапорфиринов и содержал узкую интенсивную $Q$-полосу в видимой области и уширенную полосу Сорэ в УФ-области (Рисунок 1 спектр D). Однако при растворении в хлороформе и других некоординирующих растворителях получался красно-бурый раствор, в 
ЭСП которого имелось несколько широких полос поглощения с уменьшающейся интенсивностью (Рисунок 1 спектр $A$ ) и он не был типичен для известных комплексов тетраазапорфиринов. В процессе хроматографии раствора в $\mathrm{CHCl}_{3}$ на нейтральной окиси алюминия раствор по мере прохождения по колонке менял цвет и в результате получался зеленый раствор (Рисунок 1 спектр $B$ ).

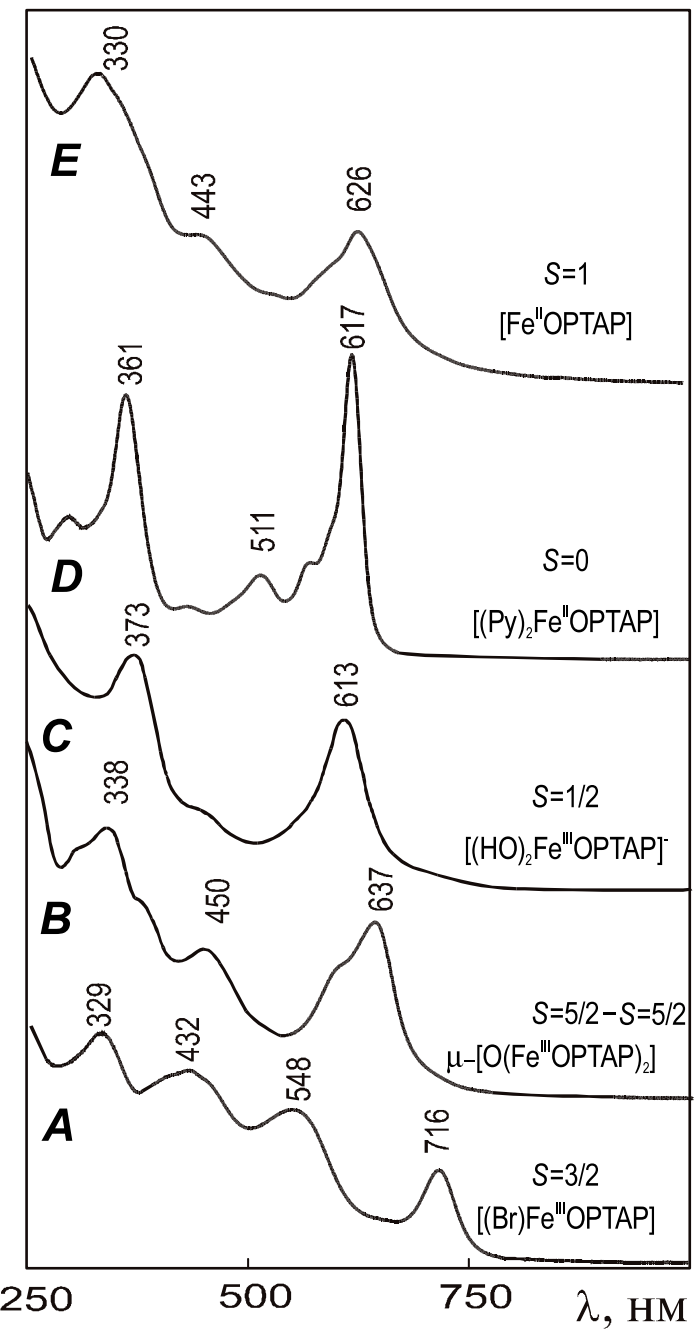

Рисунок 1. ЭСП различных координационных форм $\mathrm{Fe}-$ октафенилтетраазапорфина в дихлорметане (A-D) и толуоле (Е).

Было ясно, что мы столкнулись с основной пробле-

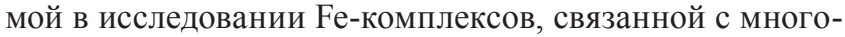
образием образуемых ими координационных форм. Решить эту проблему и сделать правильные выводы о строении было невозможно без наличия надёжных методов установления окислительного, спинового и координационного состояний атома железа. В нашем же распоряжении в то время была только электронная спектроскопия поглощения, которая наглядно демонстрировала многообразие координационных форм, но, без привлечения данных других физико-химических методов, не позволяла сделать структурные выводы. Борис Дмитриевич рекомендовал мне набраться опыта в научных центрах, занимающихся исследованием комплексов железа и приветствовал мои стажировки во Вроцлавском университете у профессора Л. ЛатосГражинского, занимавшегося исследованием $\mathrm{Fe}$ порфиринов (1987 год), а затем в 1992-94 гг. в Кильском Университете в Германии у профессора Х. Хомборга - ведущего специалиста в области спектроскопии и координационной химии комплексов фталоцианинов. Была получена возможность использования широкого арсенала современных физико-химических методов исследования, что позволило определить строение многочисленных координационных форм Fе-октафенилтетраазапорфиринов и получить достаточно полную картину их взаимных превращений.

Было установлено, ${ }^{[29-31]}$ что из реакционной смеси после темплатной циклотетрамеризации дифенилфумародинитрила с $\mathrm{Fe}(\mathrm{CO})_{5}$ в кипящем 1-бромнафталине выделяется красно-бурый пентакоординационный бромидный комплекс $\mathrm{Fe}^{\mathrm{III}}$, [(Br)Fe $\left.{ }^{\mathrm{III}} \mathrm{OPTAP}\right]$, который в процессе хроматографии на нейтральной окиси алюминия превращается в биядерный $\mu$-оксокомплекс $\mu-\mathrm{O}\left[\mathrm{Fe}^{\mathrm{III}} \mathrm{OPTAP}\right]_{2}$, а при растворении в пиридине образует фиолетовый гексакоординационный дипиридинат $\mathrm{Fe}^{\mathrm{II}}\left[(\mathrm{Py})_{2} \mathrm{Fe}^{\mathrm{II} O P T A P}\right]$ (Схема 1). При его нагревании в вакууме образуется тетракоординационный комплекс $\mathrm{Fe}^{\mathrm{II}}$ - [Fe $\left.{ }^{\mathrm{II}} \mathrm{OPTAP}\right]$, который очень неустойчив к окислению и на воздухе быстро превращается в $\mu$-оксокомплекс $\mu-\mathrm{O}\left[\mathrm{Fe}^{\mathrm{III}} \mathrm{OPTAP}\right]_{2}$. При растворении последнего в горячем пиридине снова образуется дипиридинат $\left[(\mathrm{Py})_{2} \mathrm{Fe}^{\mathrm{II} O P T A P}\right]$.

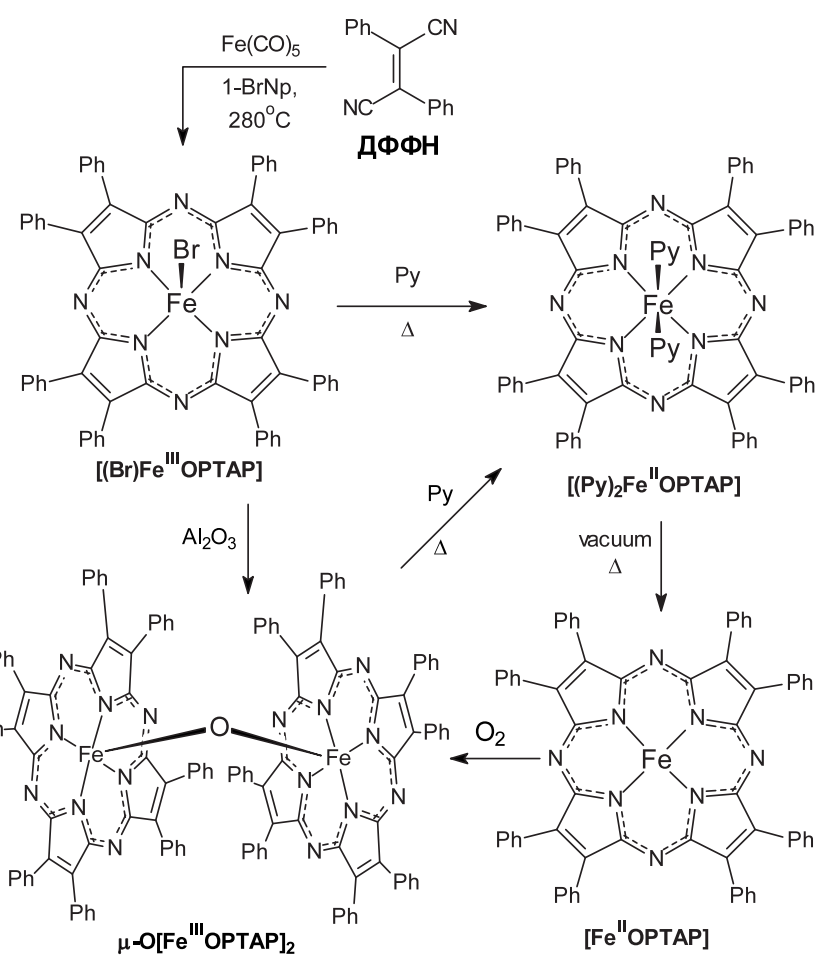

Схема 1. Синтез комплексов октафенилтетраазапорфина с железом.

Бромидный комплекс [(Br)Fe $\left.{ }^{\mathrm{III} O P T A P}\right]$, а также легко получаемые из него $\mu$-оксокомплекс $\mu-\mathrm{O}\left[\mathrm{Fe}^{\mathrm{III}} \mathrm{OPTAP}\right]_{2}$ и дипиридинат $\left[(\mathrm{Py})_{2} \mathrm{Fe}^{\mathrm{II}} \mathrm{OPTAP}\right]$ являются удобными исходными продуктами для дальнейшего синтеза различных координационных форм $\mathrm{Fe}^{\mathrm{II}}$ и $\mathrm{Fe}^{\mathrm{III}}$-октафенилтетраазапорфиринов. 
Гексакоординацчионные комплексы $\mathrm{Fe}^{I I}(S=0)$

Гексакоординационные комплексы $\mathrm{Fe}^{\mathrm{II}}$-октафенилтетраазапорфина [(L) Fe $\left.^{\mathrm{II}} \mathrm{OPTAP}\right]$, наиболее устойчивы и получаются при нагревании любой другой координационной формы комплекса октафенилтетраазапорфина c $\mathrm{Fe}^{\mathrm{II}}$ или $\mathrm{Fe}^{\mathrm{III}}$ в избытке соответствующего N-основания ( $\mathrm{L}=$ пиридины, имидазолы) ${ }^{[30-32]}$ а также в присутствии изоцианидов $(\mathrm{L}=\mathrm{RN} \equiv \mathrm{C}) .{ }^{[33]}$ Механизм восстановления $\mathrm{Fe}^{\mathrm{III}}$ до $\mathrm{Fe}^{\mathrm{II}}$ до сих пор точно не установлен, но наиболее вероятно, что в случае N-оснований восстановителем является гидроксид-анион, образующийся в присутствии следов воды. Гексакоординационные дианионные комплексы $\left[(\mathrm{A})_{2} \mathrm{Fe}^{\mathrm{II} O P T A P}\right]^{2-}$ получаются при действии избытка хорошо координирующего аниона $\left(\mathrm{A}^{-}=\mathrm{CN}^{-}\right.$, $\left.\mathrm{SCN}^{-}, \mathrm{ONC}^{-}\right)$на $\left[\left(\mathrm{L}_{2}\right) \mathrm{Fe}^{\mathrm{II}} \mathrm{OPTAP}\right]$ в некоординирующем растворителе или на [(Br)Fe $\left.\mathrm{Fe}^{\mathrm{II}} \mathrm{OPTAP}\right]$ в полярных растворителях (ацетон, ДМСО). ${ }^{[34]}$ В неполярном растворителе $\left(\mathrm{CHCl}_{3}, \mathrm{CH}_{2} \mathrm{Cl}_{2}\right)$ восстановления $\mathrm{Fe}^{\mathrm{III}}$ до $\mathrm{Fe}^{\mathrm{II}}$ не происходит и образуется моноанионный комплекс $\left[(\mathrm{A})_{2} \mathrm{Fe}^{\mathrm{III} O P T A P}\right]^{-}$(см. далее).

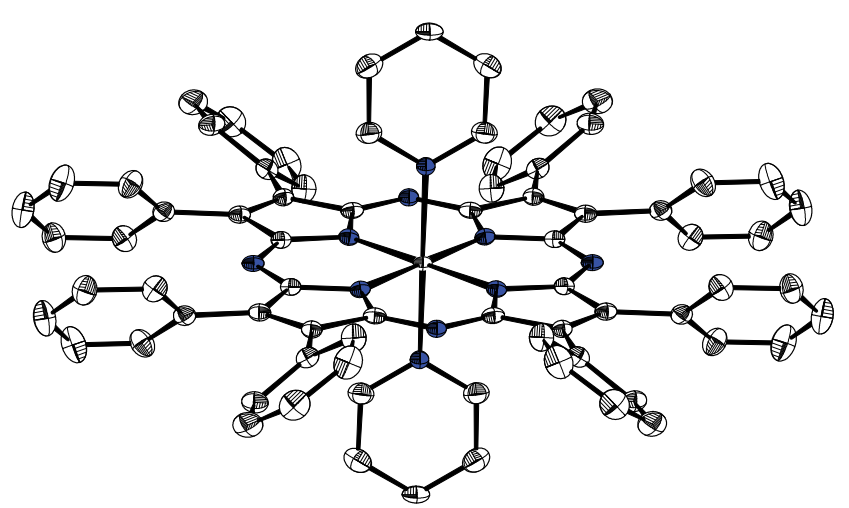

Рисунок 2. Молекулярная структура [(Ру) $\left.{ }_{2} \mathrm{Fe}^{\mathrm{II} O P T A P}\right]$.

Строение дипиридината [(Ру) ${ }_{2} \mathrm{Fe}^{\mathrm{II} O P T A P] ~ б ы л о ~}$ установлено ${ }^{[35]}$ методом рентгено-структурного анализа (Рисунок 2). Макроциклический лиганд является почти плоским (отклонения от средней плоскости не более $0.03 \AA$ ), а фенильные кольца в $\beta$-положениях повернуты относительно средней плоскости макроцикла на углы 36.6 и $49.0^{\circ}$, что делает возможным их частичное сопряжение с его ароматической $\pi$-системой. Эффект сопряжения отражается на длинах связей $\mathrm{C}_{\beta}-\mathrm{C}_{\mathrm{Ph}}$, которые короче для фенильных колец с меньшим углом поворота (1.477 и $1.486 \AA$ ). Следует отметить, что, в отличие от $\left[(\mathrm{Py})_{2} \mathrm{Fe}^{\mathrm{II}} \mathrm{OPTAP}\right]$, в комплексе мезо-тетрафенилпорфина $\left[(\mathrm{Py})_{2} \mathrm{FeTPP}\right]^{[36]}$ гораздо больший угол поворота мезофенильных колец $\left(60.7\right.$ и $\left.74.1^{\circ}\right)$ практически полностью исключает их участие в сопряжении и длина связи $\mathrm{C}_{\text {мезо }}-\mathrm{C}_{\mathrm{Ph}}$ составляет 1.49 - $1.51 \AA$. Две координированные молекулы пиридина в [(Ру) $\left.{ }_{2} \mathrm{Fe}^{\mathrm{II}} \mathrm{OPTAP}\right]$ расположены в одной плоскости, которая почти перпендикулярна средней плоскости макроцикла (угол $85.6^{\circ}$ ) и пересекает ее вдоль оси, проходящей через противоположные мезо-атомы азота (отклонение $2.8^{\circ}$ ). Такое расположение аксиальных лигандов более выгодно стерически, но менее благоприятно для их $\pi$-связывания.

Сравнение средних геометрических параметров макроциклического лиганда в [(Ру $)_{2}$ FeOPTAP] с данными по соответствующему комплексу мезо-тетрафенилпорфина $\left[(\mathrm{Py})_{2} \text { FeTPP }\right]^{[36]}$ (Таблица 1) показывает, что мезотетраазазамещение приводит к уменьшению диаметра координационной полости на $0.168 \AA$ за счет укорочения связей с мостиковым атомом $\mathrm{C}_{\alpha}-\mathrm{X}_{\text {meso }}$ и уменьшения образуемого им угла $\mathrm{C}_{\alpha} \mathrm{X}_{\text {meso }} \mathrm{C}_{\alpha}$, а также увеличения углов $\mathrm{C}_{\alpha} \mathrm{N}_{\text {pyr }} \mathrm{C}_{\alpha}$ и $\mathrm{X}_{\text {meso }} \mathrm{C}_{\alpha} \mathrm{N}_{\text {pyr }}$. При этом укорочение связей $\mathrm{C}_{\alpha}-\mathrm{N}_{\text {pyr }}$ свидетельствует об увеличении ароматичности внутреннего 16-членного макроцикла, а удлинение связей $\mathrm{C}_{\alpha}-\mathrm{C}_{\beta}$ - об уменьшении эффекта его сопряжения с $\pi$-связями этиленовых фрагментов, т.е. об их изоляции.

Таблица 1. Влияние тетраазазамещения на средние геометрические параметры порфиринового макроцикла в комплексах железа(II). Длины связей в $\AA$, углы в градусах $\left({ }^{\circ}\right)$

\begin{tabular}{cccc}
\hline $\begin{array}{c}\text { Геометрич. } \\
\text { параметр }\end{array}$ & {$\left[(\text { Ру })_{2}\right.$ FeOPTAР $]$} & {$\left[(\text { Ру })_{2} \text { FeTPР }\right]^{[36]}$} & Разница $\Delta$ \\
\hline $\mathrm{C}_{\alpha}-\mathrm{X}_{\text {meso }}$ & 1.332 & 1.398 & -0.066 \\
$\mathrm{C}_{\alpha}-\mathrm{N}_{\text {pyr }}$ & 1.371 & 1.381 & -0.010 \\
$\mathrm{C}_{\alpha}-\mathrm{C}_{\beta}$ & 1.467 & 1.444 & +0.023 \\
$\mathrm{C}_{\beta}-\mathrm{C}_{\beta}$ & 1.358 & 1.360 & -0.002 \\
$\mathrm{~N}_{\text {pyr }}-\mathrm{C}_{\mathrm{t}}$ & 1.918 & 2.002 & -0.084 \\
$\mathrm{M}_{\mathrm{C}} \mathrm{C}_{\mathrm{t}}$ & 0 & 0 & 0 \\
$\mathrm{~N}_{\text {pyr }}-\mathrm{M}$ & 1.918 & 2.002 & -0.084 \\
$\mathrm{M}^{-} \mathrm{L}_{\text {ax }}$ & 2.044 & 2.037 & +0.007 \\
$\angle \mathrm{C}_{\alpha} \mathrm{X}_{\text {meso }} \mathrm{C}_{\alpha}$ & 121.9 & 123.4 & -1.5 \\
$\angle \mathrm{C}_{\alpha} \mathrm{N}_{\text {pyr }} \mathrm{C}_{\alpha}$ & 106.1 & 105.2 & +0.9 \\
$\angle \mathrm{X}_{\text {meso }} \mathrm{C}_{\alpha} \mathrm{N}_{\text {pyr }}$ & 127.1 & 125.9 & +1.2 \\
\hline
\end{tabular}

Гексакоординационные комплексы $\mathrm{Fe}^{\mathrm{II}} \mathrm{c}$ $\mathrm{N}$-основаниями, ${ }^{[30]}$ изоцианидами ${ }^{[33]}$ и цианидом ${ }^{[34]}$ являются низкоспиновыми $(S=0)$. В их ПМР спектрах наблюдаются характерные для диамагнитных соединений узкие сигналы протонов макроциклического лиганда и координированных аксиальных лигандов. Как и в случае других диамагнитных комплексов октафенилтетраазапорфина, например, с индием(III), ${ }^{[37,38]}$ сигналы орто-протонов фенильных колец, дезэкранированных $\pi$-кольцевым током макроцикла, наблюдаются в более слабом поле, чем сигналы мета- и парапротонов, часто сливающихся в один мультиплет (Таблица 2). Сигналы протонов координированного пиридина, находящегося в области экранирования испытывают сильнопольный сдвиг, ослабляющийся по мере удаления от макроцикла ( $\alpha$-Ру $>\beta$-Ру $>\gamma$-Ру).

Параметры Мессбауэровских спектров для [(L), $\left.\mathrm{Fe}^{\mathrm{II}} \mathrm{OPTAP}\right](\mathrm{L}=\mathrm{Py}, \mathrm{HIm})$ (изомерный сдвиг $\delta_{\mathrm{Fe}}-$ 0,1-0,2 мм/с и квадрупольное расщепление $\Delta E_{\mathrm{Q}}-2,1-2,3$ мм/с, Таблица 3) также являются характерными для низкоспиновых комплексов $\mathrm{Fe}^{\mathrm{II}} \cdot{ }^{[39]}$ При координации изоцианида и цианида, являющихся более сильнопольными лигандами, чем $\mathrm{N}$-основания, величина $\delta_{\mathrm{Fe}}$ несколько уменьшается, а расщепление $\Delta E_{\mathrm{Q}}$ сокращается более чем в 2 раза (до 1 мм/с).

Электронные спектры поглощения (ЭСП) комплексов [(L) $\mathrm{Fe}^{\mathrm{II} O P T A P] ~ с ~ п и р и д и н а м и ~}{ }^{[30]}$ и изоциани- 
Таблица 2. Химические сдвиги ${ }^{1} \mathrm{H}$ ЯМР спектрах комплексов октафенилтетраазапорфина.

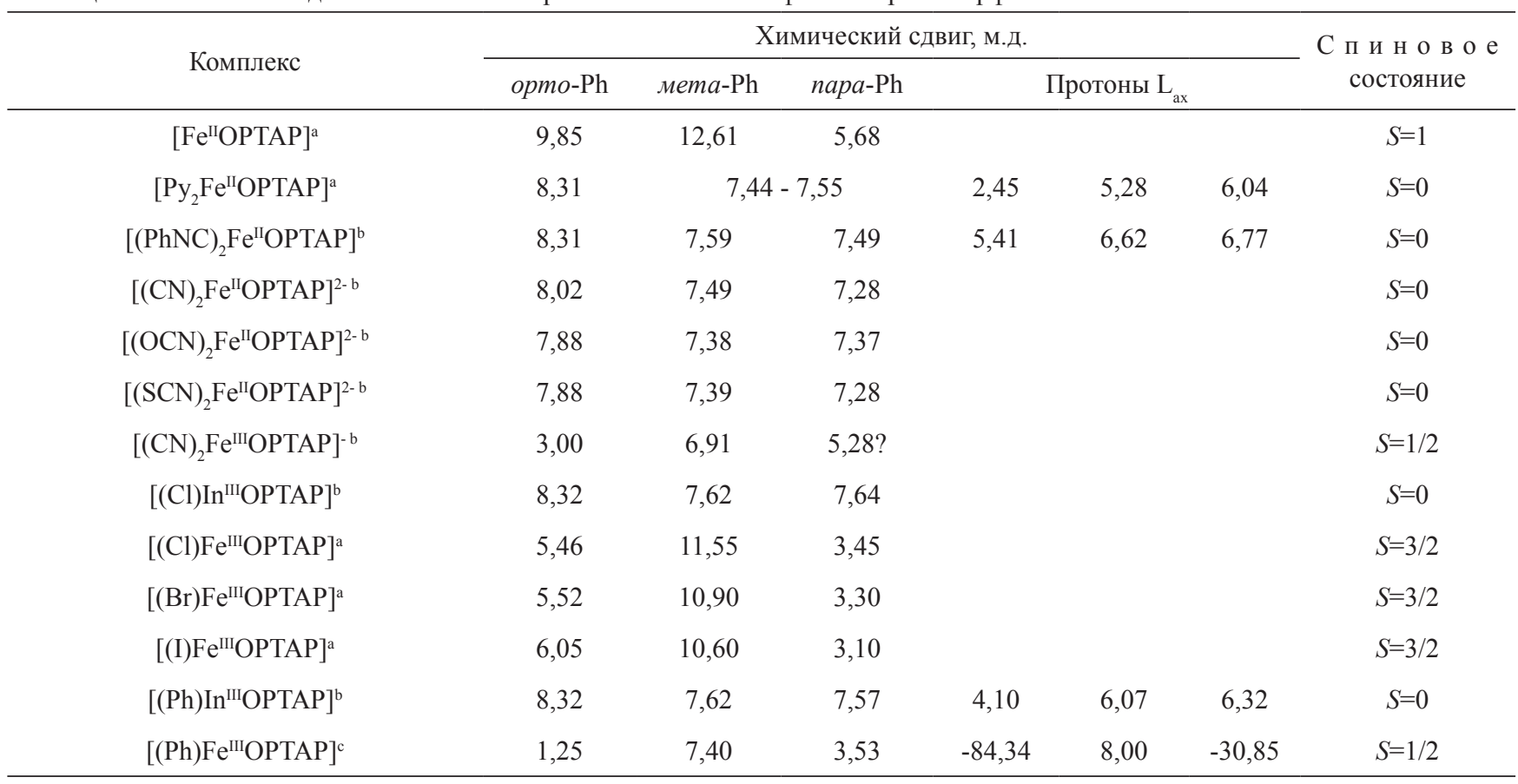

a- $\mathrm{CDCl}_{3} ;{ }^{\text {b }}-\mathrm{CD}_{2} \mathrm{Cl}_{2},{ }^{\text {c }}-\mathrm{PhMe}-d_{8}$.

дами $^{[33]}$ характерны для диамагнитных комплексов октафенилтетраазапорфина и содержат узкую и интенсивную $Q$-полосу в длинноволновой области при 610-620 нм и полосу Сорэ в УФ-области при 360-380 нм (см. Рисунок 3). Между ними наблюдается ряд менее интенсивных полос переноса заряда (ПЗ). В случае $\left[\mathrm{Py}_{2} \mathrm{Fe}^{\mathrm{II}} \mathrm{OPTAP}\right]$ на основании данных резонансной Рамановской спектроскопии ${ }^{[40]}$ полоса при 513 нм и плечо при 480 нм были отнесены к ПЗ переходам $\mathrm{Fe} \rightarrow \mathrm{OPTAP}$ $\left(d_{\pi} \rightarrow 2 b_{1 u}^{*}\right)$ и $\mathrm{Fe} \rightarrow \mathrm{Py}\left(d_{\pi} \rightarrow\left(\pi^{*}\right)_{\mathrm{Py}}\right)$, полоса при 430 нм к П3 переходу ОРТАР $\rightarrow \mathrm{Fe} \quad\left(3 a_{2 u} \rightarrow 3 d_{z^{2}}\right)$. Интенсивность полосы ПЗ $\mathrm{Fe} \rightarrow$ ОРТАР сильно зависит от электронной плотности на атоме железа: она практически исчезает при координации изоцианида, проявляющего сильный обратный дативный $\pi$-эффект $\mathrm{Fe} \Rightarrow \mathrm{C} \equiv \mathrm{NR}$, и возрастает в случае комплекса с имидазолом [( $\left.\mathrm{ImH})_{2} \mathrm{Fe}^{\mathrm{II}} \mathrm{OPTAP}\right]$, обладающем $\pi$-донорными свойствами, и, особенно, в дианионном цианидном комплексе $\left[(\mathrm{CN})_{2} \mathrm{Fe}^{\mathrm{II} O P T A P}\right]^{2-}$ (Рисунок 3).

Исследование реакции замещения экстралигандов в гексакоординационных комплексах $\mathrm{Fe}^{\mathrm{II}}$-октафенилтетраазапорфина [(L) ${ }_{2} \mathrm{FeOPTAP]} \mathrm{показало,} \mathrm{что} \mathrm{наиболее}$ устойчивые комплексы образуются с С-донорными лигандами (цианидом, ${ }^{[25]}$ изоцианидами ${ }^{[26]}$ ), проявляющими максимальные $\sigma$-донорный и $\pi$-акцепторные эффекты координации. При этом бис-цианидные и

Таблица 3. Параметры Мессбауэровских спектров Fе-комплексов октафенилтетраазапорфина.

\begin{tabular}{|c|c|c|c|c|c|c|c|c|c|}
\hline Соединение & $\delta_{\mathrm{Fe}}, \mathrm{MM} / \mathrm{c}$ & $\begin{array}{l}\Delta E_{\mathrm{O}} \\
\mathrm{MM} / \mathrm{c}\end{array}$ & $\mathrm{T}, \mathrm{K}$ & $\mu_{\mathrm{ef}}$ & Соединение & $\begin{array}{c}\delta_{\mathrm{Fe}}, \\
\mathrm{MM} / \mathrm{C}\end{array}$ & $\begin{array}{l}\Delta E_{\mathrm{Q}}, \\
\mathrm{MM} / \mathrm{c}\end{array}$ & $\mathrm{T}, \mathrm{K}$ & $\mu_{\text {ef }}$ \\
\hline \multicolumn{5}{|c|}{$\mathrm{Fe}^{\mathrm{II}} S=1$} & \multicolumn{5}{|c|}{$\mathrm{Fe}^{\mathrm{III}} S=3 / 2$} \\
\hline \multirow[t]{2}{*}{ [FeOPTAP] } & 0.05 & 2.53 & RT & 3.80 & [(F)FeOPTAP $]$ & 0.28 & 2.99 & 140 & \\
\hline & \multicolumn{2}{|l|}{$\mathrm{Fe}^{\mathrm{II}} S=0$} & & & [(Cl)FeOPTAP $]$ & 0.26 & 2.85 & 82 & 3.44 \\
\hline$\left[(\mathrm{Py})_{2} \mathrm{FeOPTAP}\right]$ & 0.21 & 2.26 & RT & диам & {$[(\mathrm{Br}) \mathrm{FeOPTAP}]$} & 0.25 & 3.04 & 82 & 2.98 \\
\hline$\left[(\mathrm{HIm})_{2} \mathrm{FeOPTAP}\right]$ & 0.18 & 2.12 & RT & диам & [(I)FeOPTAP $]$ & 0.24 & 3.39 & 82 & \\
\hline$\left[(\mathrm{CyNC})_{2} \mathrm{FeOPTAP}\right]$ & 0.12 & 0.99 & 295 & диам & {$\left[\left(\mathrm{HSO}_{4}\right) \mathrm{FeOPTAP}\right]$} & 0.28 & 3.58 & 82 & \\
\hline \multirow[t]{2}{*}[(\mathrm{CN})_{2}\mathrm{FeOPTAP}]{$^{2-}$} & 0.15 & 1.00 & 82 & диам & [(CN)FeOPTAP $]$ & 0.25 & 3.04 & 82 & \\
\hline & 0.06 & 1.01 & 298 & & [(SCN)FeOPTAP $]$ & 0.27 & 3.68 & 82 & \\
\hline \multicolumn{5}{|c|}{$\mathrm{Fe}^{\mathrm{III}} S=1 / 2$} & \multicolumn{5}{|c|}{$\mathrm{Fe}^{\mathrm{III}} S=5 / 2$} \\
\hline$\left[(\mathrm{Im})_{2} \mathrm{FeOPTAP}\right]^{+}$ & 0.15 & 2.26 & 82 & 1.31 & {$\left[\mu-\mathrm{O}(\mathrm{FeOPTAP})_{2}\right]$} & 0.40 & 0.89 & RT & 2.42 \\
\hline \multirow[t]{2}{*}[(\mathrm{CN})_{2}\mathrm{FeOPTAP}]{$^{-}$} & 0.12 & 1.17 & 82 & 1.60 & \multicolumn{5}{|c|}{$\mathrm{Fe}^{\mathrm{III1} / 2} S=1 / 2$} \\
\hline & -0.05 & 1.07 & 298 & & {$\left[\mu-\mathrm{N}(\mathrm{FeOPTAP})_{2}\right]$} & -0.04 & 1.77 & $\mathrm{RT}$ & 2.24 \\
\hline
\end{tabular}




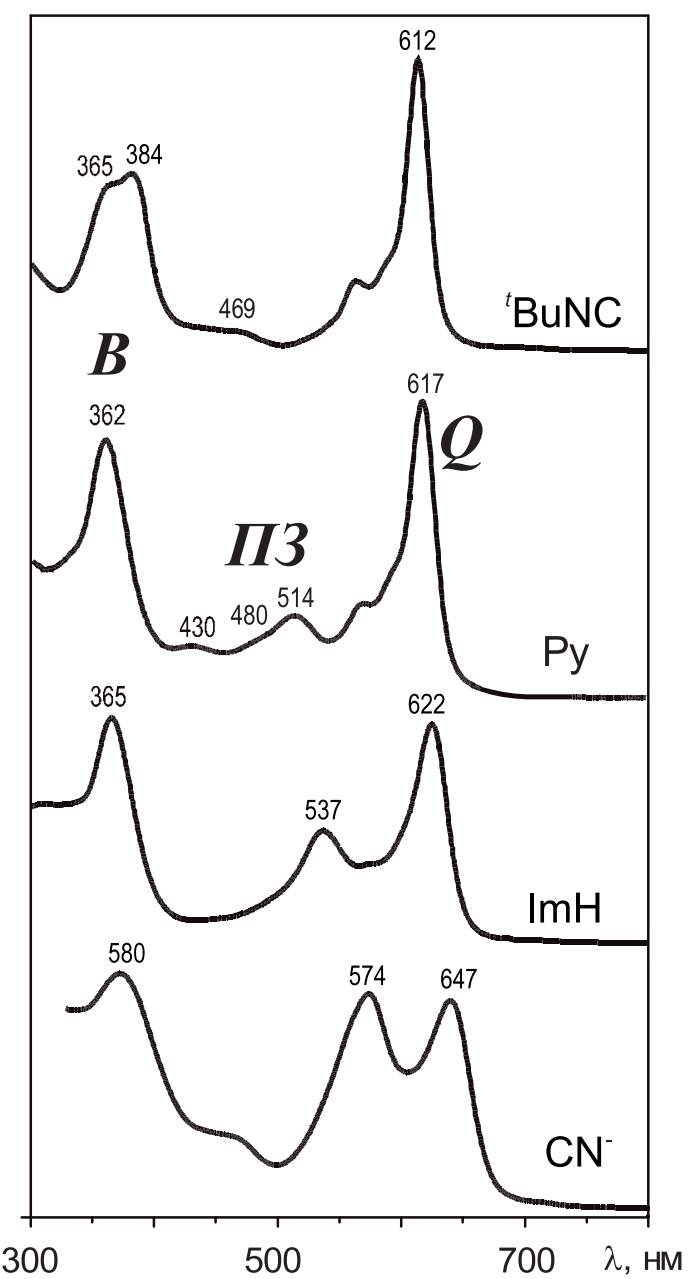

Рисунок 3. ЭСП низкоспиновых гексакоординационных комплексов $\mathrm{Fe}^{\mathrm{II}}$-октафенилтетраазапорфина [(L) $\left.{ }_{2} \mathrm{FeOPTAP}\right]$.

бис-изоцианидные комплексы вследствие проявления транс-эффекта, в присутствии $\mathrm{N}$-оснований легко превращаются в смешаннолигандные комплексы. Рисунок 4 показывает изменение ЭСП раствора дицианидного комплекса $\left[(\mathrm{CN})_{2} \mathrm{Fe}^{\mathrm{II}} \mathrm{OPTAP}\right]^{2-}$ в толуоле (спектр 1) при добавлении пиридина в процессе превращения в смешаннолигандный комплекс [(Ру)(CN)Fe $\left.{ }^{\mathrm{II} O P T A P}\right]^{-}$(спектр 2). Установлено, что замещение экстралигандов протекает по диссоциативному механизму, лимитирующей стадией которого является образование пентакоординационного интермедиата. При увеличении концентрации пиридина в 370 раз (с 0,025 до 9.27 М) скорость этой реакции не только не увеличивается, а наоборот, за счет изменения сольватационных свойств среды, уменьшается в 2,3 раза с 0,00122 до 0,000532 $\mathrm{c}^{-1}$ (при $298 \mathrm{~K}$ ). ${ }^{[1]}$ Замещение второго цианида-аниона требует гораздо более жёстких условий и дипиридинат [(Ру) $\left.{ }_{2} \mathrm{Fe}^{\mathrm{II}} \mathrm{OPTAP}\right]$ медленно образуется лишь при длительном нагревании смешаннолигандного комплекса $\left[(\mathrm{Py})(\mathrm{CN}) \mathrm{Fe}^{\mathrm{II}} \mathrm{OPTAP}\right]^{-}$в избытке пиридина (Рисунок 4 спектр 3).

При изучении реакции замещения лигандов в бисизоцианидных комплексах [(RNC) $\left.{ }_{2} \mathrm{Fe}^{\mathrm{II}} \mathrm{OPTAP}\right](\mathrm{R}$ $=t$ - $\mathrm{Bu}, \mathrm{Ph}$, циклогексил) на $\mathrm{N}$-основания (Ру, 4-MePy, 1-MeIm), было установлено, ${ }^{[26]}$ замещение первого изоцианида проходит практически мгновенно при концентрациях N-основания сопоставимыми со стехиометрическими, а замещение второго изоцианида тре-

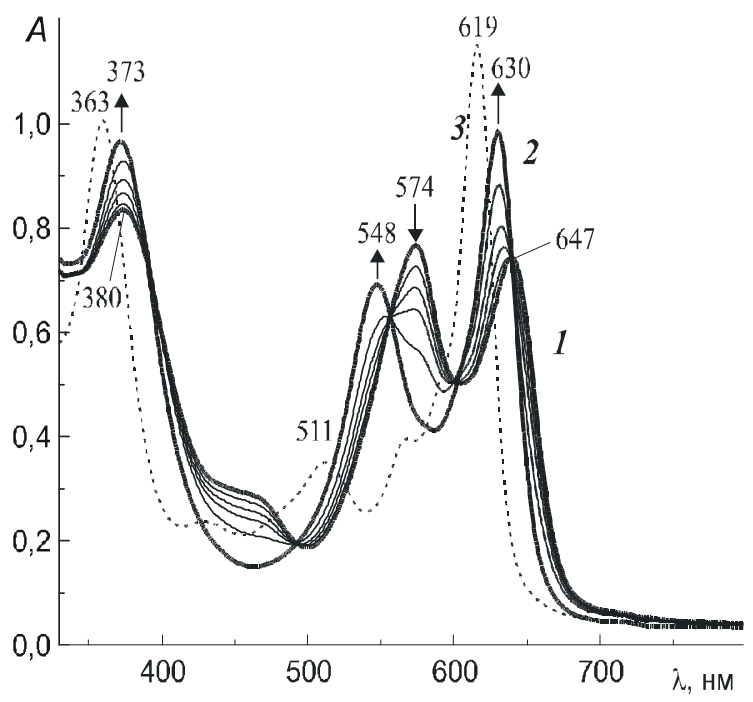

Рисунок 4. ЭСП раствора $\left[(\mathrm{CN})_{2} \mathrm{Fe}^{\mathrm{II}} \mathrm{OPTAP}\right]^{2-}$ в толуоле (1) и его изменения после добавки пиридина $([\mathrm{Py}]=8.23 \mathrm{M}): 2$ - образование [(Pу)(CN)Fe" OPTAP] при 298 К, 3 - превращение в $\left[(\text { Ру })_{2} \mathrm{Fe}^{\mathrm{II}} \mathrm{OPTAP}\right]$ при $373 \mathrm{~K}$.

бует 100-1000-кратного избытка N-основания и проходит достаточно медленно. Так $\mathrm{p} K_{э 1}$ и $\mathrm{p} K_{э 2}$ для реакции [(t-BuNC $)_{2} \mathrm{Fe}^{\mathrm{II} O P T A P] ~ в ~ т о л у о л е ~ с ~ Р у ~ п р и ~} 298 \mathrm{~K}$ составляют $0,86 \pm 0,04$ и $3,55 \pm 0,09$, а с HIm $-0,75 \pm 0,331,54 \pm 0,03$, соответственно. Величина $k_{2}$ для замещения второго $t$-BuNC на Ру составляет 0,0235 $\pm 0,0003 \mathrm{c}^{-1}$, а на 1-MeIm $0,0121 \pm 0,0001 \mathrm{c}^{-1}$.

Были получены также полимерные комплексы $\mathrm{Fe}^{\mathrm{II}}$-октафенилтетраазапорфина с бидентатными N- и C-координирующими лигандами (пиразин, диизоцианодурол) (L)(FeOPTAP) $[(\mu-\mathrm{L})(\mathrm{FeOPTAP})]_{n}(\mathrm{~L}) \cdot{ }^{[33]}$ В отличие от аналогичных полимерных $\mu$-комплексов в ряду $\mathrm{Fe}^{\mathrm{II}}$ фталоцианинов они не обнаружили полупроводниковых свойств. Это является следствием более высокого окислительного потенциала порфиразинового макроцикла.

мезо-Тетраазазамещение в порфириновом макроцикле, усиливая его $\pi$-акцепторные свойства, стабилизирует комплексы с металлами в низких степенях окисления. Поэтому комплексы $\mathrm{Fe}^{\mathrm{II}}$ с октафенилтетраазапорфином гораздо устойчивее к окислению, чем комплексы $\mathrm{Fe}^{\mathrm{II}}$ с порфиринами. Проведенные электрохимические исследования (Таблица 4) показали, что потенциал окисления $\mathrm{Fe}^{\mathrm{II}} / \mathrm{Fe}^{\mathrm{III}}$ в комплексах октафенилтетраазапорфина на 0,3-0,5 В выше по сравнению с соответствующими комплексами $\mathrm{Fe}-$ порфиринов. ${ }^{[42]}$ Так для [(Ру $\left.{ }_{2} \mathrm{Fe}^{\mathrm{II}} \mathrm{OPTAP}\right]$ окисление $\mathrm{Fe}^{\mathrm{II}} / \mathrm{Fe}^{\mathrm{III}}$ происходит лишь при $+0.51 \mathrm{~B}$, в то время как для $\left[(\mathrm{Py})_{2} \mathrm{Fe}^{\mathrm{II}} \mathrm{OEP}\right]$ оно наблюдается уже при -0,15 B. ${ }^{[43]}$ Однако в кислых средах, вследствие отрыва и связывания экстралиганда L, комплексы $\left[(\mathrm{L})_{2} \mathrm{Fe}^{\mathrm{II}} \mathrm{OPTAP}\right]$ легко окисляются на воздухе до

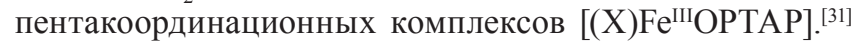
Так для изоцианидного комплекса [(PhNC) $)_{2} \mathrm{Fe}^{\text {II OPTAP] }}$ в среде $\mathrm{CH}_{2} \mathrm{Cl}_{2}-\mathrm{CF}_{3} \mathrm{COOH}$ удалось изучить только первую стадию кислотно-основного взаимодействия с мезо-атомом азота и получить константу устойчивости первой кислотной формы $\mathrm{p} K_{1}=2,16$, т.к. при концентрациях кислоты, необходимых для протонирования второго мезо-атома, наблюдалось окисление с образованием [( $\left.\left.\mathrm{CF}_{3} \mathrm{COO}\right) \mathrm{Fe}^{\mathrm{III}} \mathrm{OPTAP}\right] .{ }^{[26]}$ 
Таблица 4. Потенциалы полуволн редокс-процессов $\mathrm{Fe}-$ комплексов октафенилтетраазапорфина в $\mathrm{CH}_{2} \mathrm{Cl}_{2}$.

\begin{tabular}{|c|c|c|c|c|}
\hline \multirow{2}{*}{ Комплекс } & \multicolumn{4}{|c|}{ Потенциалы полуволн $E_{1 / 2}$, В (н.к.э.) } \\
\hline & OPTAP $^{2-/}$ OPTAP $^{3-}$ & $\mathrm{Fe}^{\mathrm{II}} / \mathrm{Fe}^{\mathrm{I}}$ & $\mathrm{Fe}^{\mathrm{III}} / \mathrm{Fe}^{\mathrm{II}}$ & OPTAP $^{2-/}$ OPTAP \\
\hline$\left[(\mathrm{Py})_{2} \mathrm{Fe}^{\mathrm{II} O P T A P}\right]$ & $-0,98$ & $-0,60$ & $+0,51$ & $+0,98$ \\
\hline$\left[(\mathrm{CN})_{2} \mathrm{Fe}^{\mathrm{II}} \mathrm{OPTAP}\right]^{2-}$ & $-1,34$ & $-1,04$ & $+0,22$ & $+1,13$ \\
\hline$\left[\left({ }^{\mathrm{t} B u N C}\right)_{2} \mathrm{Fe}^{\mathrm{II}} \mathrm{OPTAP}\right]$ & $-1,21$ & $-0,89$ & $+0,75$ & \\
\hline$\left[(\mathrm{HIm})_{2} \mathrm{Fe}^{\mathrm{III}} \mathrm{OPTAP}\right]^{+}$ & & & $+0,22$ & \\
\hline$\left[\left(\mathrm{ClO}_{4}\right) \mathrm{Fe}^{\mathrm{III}} \mathrm{OPTAP}\right]$ & $-1,05$ & $-0,34$ & $+0,35$ & $+1,06$ \\
\hline$\left[(\mathrm{Cl}) \mathrm{Fe}^{\mathrm{III}} \mathrm{OPTAP}\right]$ & & $-0,39$ & $+0,02$ & \\
\hline
\end{tabular}

\section{Тетракоординационный комплекс $F e^{I I}(S=1)$}

Тетракоординационный комплекс [Fe $\left.{ }^{\mathrm{II} O P T A P}\right]$ получается из гексакоординационных комплексов $\mathrm{Fe}^{\mathrm{II}}$ $\left[(\mathrm{L})_{2} \mathrm{Fe}^{\mathrm{II} O P T A P] ~ п р и ~ и х ~ н а г р е в а н и и ~ в ~ в а к у у м е ~}{ }^{[30]}\right.$ или при восстановлении цинковой пылью раствора $[(\mathrm{X})$ $\mathrm{Fe}^{\mathrm{III}} \mathrm{OPTAP]} \mathrm{в} \mathrm{инертном} \mathrm{растворителе.}{ }^{[31]}$ [Fe $\left.{ }^{\mathrm{II}} \mathrm{OPTAP}\right]$ неустойчив к окислению и на воздухе легко превращается в $\mu$-оксокомплекс $\mathrm{Fe}^{\mathrm{III}} \mu-\mathrm{O}\left[\mathrm{Fe}^{\mathrm{III}} \mathrm{OPTAP}\right]_{2}$. Полосы $\pi \rightarrow \pi^{*}$ переходов в ЭСП тетракоординационного комплекса [Fe' $\mathrm{FPTAP}$ несколько уширены (Рисунок 1 спектр E), что является характерным признаком сильного взаимодействия $\pi$-МО с частично заполненными $d$-орбиталями. По сравнению с диамагнитными комплексами [(L), $\left.\mathrm{Fe}^{\mathrm{II} O P T A P}\right]$ сигналы протонов фенильных колец в ${ }^{1} \mathrm{H}$ ЯМР спектре [Fe $\left.{ }^{\mathrm{II}} \mathrm{OPTAP}\right]$ уширены и испытывают существенный парамагнитный сдвиг (Таблица 2), направление которого свидетельствует о делокализации спиновой плотности как по дипольному, так и по $\pi$-контактному механизмам. Данные измерений магнитной восприимчивости, а также Мессбауэровской спектроскопии (Таблица 3) позволили сделать вывод о том, что атом железа в составе тетракоординационного комплекса [Fe $\left.{ }^{\mathrm{II}} \mathrm{OPTAP}\right]$ имеет промежуточное спиновое состояние $S=1$ и конфигурацию $\left(d_{\mathrm{xy}}\right)^{2}\left(d_{z^{2}}\right)^{2}\left(d_{\pi}\right)^{2} \cdot{ }^{[30]}$

\section{Пентакоординациионые комплексы $\mathrm{Fe}^{I I I}(S=3 / 2)$}

Пентакоординационные комплексы Fe лигандами [(X)Fe $\left.{ }^{I I I} \mathrm{OPTAP}\right]\left(\mathrm{X}^{-}-\right.$анион сильной минеральной или карбоновой кислоты) образуются при обработке растворов гексакоординационных комплексов $\mathrm{Fe}^{\mathrm{II}}$ (на воздухе) и $\mathrm{Fe}^{\mathrm{III}}$ с N-основаниями ([(L) $\left.{ }_{2} \mathrm{Fe}^{\mathrm{II}} \mathrm{OPTAP}\right]$ и $\left.\left[(\mathrm{L})_{2} \mathrm{Fe}^{\mathrm{III}} \mathrm{OPTAP}\right]^{+}\right)$в некоординирующем растворителе соответствующей водной минеральной кислотой НХ или из биядерного $\mu$-оксокомплекса $\mu-\mathrm{O}\left[\mathrm{Fe}^{\mathrm{III} O P T A P}\right]_{2}$ в присутствии кислоты НХ. ${ }^{[31,44]}$ Для замещения ацидолиганда $\mathrm{X}^{-}$на другой ацидолиганд $\mathrm{Y}^{-}$удобно перевести $[(\mathrm{X})$ $\left.\mathrm{Fe}^{\mathrm{III}} \mathrm{OPTAP}\right]$ в дигидроксокомплекс [(HO) $\left.{ }_{2} \mathrm{Fe}^{\mathrm{III}} \mathrm{OPTAP}\right]^{-}$ растворением в метанольно-ацетоновом растворе КОН и далее при выливании в 10-15\%-ный водный раствор

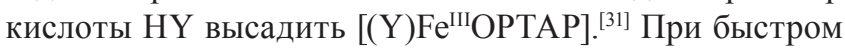
высаждении из раствора в конц. серной кислоте в воду гексакоординационных комплексов $\mathrm{Fe}^{\mathrm{II}}$ и $\mathrm{Fe}^{\mathrm{III}} \mathrm{c}$ $\mathrm{N}$-основаниями, а также пентакоординационных комплексов со слабокоординирующими анионами сильных кислот образуется гидросульфатный комплекс [( $\left.\mathrm{HSO}_{4}\right)$
$\mathrm{Fe}^{\mathrm{III} O P T A P] .[4]}$ Однако, в этих условиях не происходит замещения сильнокоординирующего цианиданиона и из дицианокомплексов $\left[(\mathrm{CN})_{2} \mathrm{Fe}^{\mathrm{II}} \mathrm{OPTAP}\right]^{2-}$ и $\left[(\mathrm{CN})_{2} \mathrm{Fe}^{\mathrm{III}} \mathrm{OPTAP}\right]^{-}$образуется не гидросульфатный, а моноцианидный комплекс [(CN)Fe $\left.{ }^{I I I} \mathrm{OPTAP}\right] .^{[34]}$

Совокупность данных по магнитной восприимчивости, Мессбауэровским, ${ }^{1} \mathrm{H}$ ЯМР и ЭПР спектрам позволила сделать вывод о том, что в ацидокомплексах $\left[(\mathrm{X}) \mathrm{Fe}^{\mathrm{III}} \mathrm{OPTAP}\right]$ атом $\mathrm{Fe}^{\mathrm{III}}$ имеет промежуточное спиновое состояние $S=3 / 2$. ${ }^{[31]}$

Магнитный момент $\left(\mu_{\text {eff }}\right)$ для твердых образцов не зависит от температуры в измеренном интервале 87-310 К и составляет $3,44 \pm 0,08 \mu_{\mathrm{B}}$ для [(Cl)FeOPTAP]

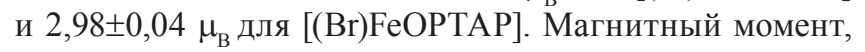
измеренный для $[(\mathrm{Br}) \mathrm{FeOPTAP}]$ в растворе $\mathrm{CDCl}_{3}$ по методу Эванса равен 4,64 $\mu_{\mathrm{B}}$. Эти значения $\mu_{\text {eff }}$ значительно отличаются от чисто спиновых величин для высоко- и низкоспинового состояний $\mathrm{Fe}^{\mathrm{III}}\left(5,92 \mu_{\mathrm{B}}\right.$ для $S=5 / 2$ и $1,73 \mu_{\text {в }}$ для $S=1 / 2$ ) и приближаются к величине $3,87 \mu_{\mathrm{B}}$, ожидаемой для промежуточного спинового состояния $S=3 / 2$. Тот факт, что в случае твердых образцов наблюдаемое значение $\mu_{\text {eff }}$ несколько меньше чисто спинового значения для $S=3 / 2$, объясняется, вероятно, небольшой примесью (1-2\%) $\mu$-оксокомплекса $\left[\mu-\mathrm{O}(\mathrm{FeOPTAP})_{2}\right]$, образование которого трудно избежать при проведении синтеза с использованием водных растворов. Галогенидные комплексы $\mathrm{Fe}^{\mathrm{III}}$-порфиринов, являясь высокоспиновыми, имеют магнитный момент $5,9 \mu_{\text {в }}$ при 298 K. $^{[45]}$

Мессбауэровские спектры (Таблица 3) также подтверждают, что в [(X)FeOPTAР] атом $\mathrm{Fe}^{\mathrm{III}}$ имеет спин $S=3 / 2$. Большая величина квадрупольного расщепления $\left(\Delta E_{\mathrm{Q}}>2,7\right.$ мм/с) отличает промежуточноспиновые комплексы $\mathrm{Fe}^{\mathrm{III}}$ от низкоспиновых $\left(\Delta E_{\mathrm{Q}} \approx 2,0-2,6 \mathrm{Mм} / \mathrm{c}\right)$ и особенно от высокоспиновых комплексов $\left(\Delta E_{\mathrm{Q}} \approx 0,4-\right.$ $1,2 \mathrm{MM} / \mathrm{c}) .{ }^{[39]}$

Параметры ЭПР спектра $g_{\perp}=4,46, \mathrm{~g}_{\|}=2,00$, полученные для $[(\mathrm{Cl}) \mathrm{FeOPTAP}]$ в толуоле при $77 \mathrm{~K}$ также указывают на спиновое состояние атома железа $S=3 / 2$. Для низкоспиновых комплексов $\mathrm{Fe}^{\mathrm{III}}$ величина $g$-факторов лежит в пределах 2,0-2,5, а для высокоспиновых $g_{\perp} \approx 6$. На промежуточное спиновое состояние атома железа указывает и направление изотропного сдвига сигналов протонов $\beta$-фенильных колец в [(Hal)FeOPTAP] (Таблица 2). В высокоспиновых комплексах $\mathrm{Fe}^{\mathrm{III}}$-порфиринов делокализация неспаренного электрона $\mathrm{c} d_{\mathrm{x} 2 \text {-у2 }}$ орбитали по б-контактному механизму орбитали вызывает 
слабопольный сдвиг сигналов протонов $\mathrm{H}_{\beta}$ и $\mathrm{R}_{\beta}{ }^{[46]}$ Наблюдаемый сильнопольный сдвиг сигналов ортои nара-протонов (на 2,2-2,8 и 4,0-4,4 м.д.) указывает на доминирующее влияние $\pi$-контактного механизма делокализации спиновой плотности с $d_{\pi}$-орбиталей. Дипольный механизм вызывает слабопольный сигнала мета-протонов на 3-4 м.д. и частично компенсирует действие $\pi$-контактного механизма в пара- и, особенно, в орто-положениях.

Следует отметить, что пентакоординационные галогенидные комплексы $\mathrm{Fe}^{\mathrm{III}}$-порфиринов, например, $\left[(\mathrm{Hal}) \mathrm{Fe}^{\mathrm{III}} \mathrm{OEP}\right]$ и [(Hal)Fe $\left.\mathrm{Fe}^{\mathrm{III}} \mathrm{TPP}\right]$ являются высокоспиновыми $(S=5 / 2)$, и лишь для комплексов со слабокоординирующими анионами, например, с перхлоратом, наблюдается смешанное промежуточновысокоспиновое состояние $(S=3 / 2 \div 5 / 2)$. $^{[15,16]}$ Ацидокомплексы фталоцианина при комнатной температуре также имеют смешанное спиновое состояние $S=3 / 2 \div 5 / 2 .{ }^{[19 \mathrm{~g}]}$ Причиной стабилизации спинового состояния $S=3 / 2$ в пентакоординационных ацидокомплексах $\mathrm{Fe}^{\mathrm{III}}$-октафенилтетраазапорфина являются происходящее при мезо-тетраазазамещении уменьшение размеров координационной полости макроциклического лиганда и усиление его $\pi$-акцепторных свойств. В результате создаются лучшие условия для $\sigma$-взаимодействия между $d_{\mathrm{x}^{2}-\mathrm{y}^{2}}$-орбиталями атома $\mathrm{Fe}^{\mathrm{III}}$ и $\sigma$-орбиталями координирующих атомов азота макроцикла, и усиливается обратное дативное $\pi$-взаимодействие $d_{\pi}$-орбиталей с $\pi *$-орбиталями макроцикла. В $\mathrm{Fe}^{\mathrm{III}}$-комплексе фталоцианина мезо-азазамещение также приводит к усилению б-взаимодействия макроцикла c $d_{\mathrm{x}^{2}-\mathrm{y}^{2}}$-орбиталями, но усиление $\pi$-акцепторных свойств компенсируется эффектом бензоаннелирования. По этой причине комплекс [( $\left.\left.\mathrm{HSO}_{4}\right) \mathrm{FeOPTAP}\right]$ оказался значительно устойчивее к протолитической диссоциации в конц. $\mathrm{H}_{2} \mathrm{SO}_{4}\left(k_{\text {эф }}=8,8 \times 10^{-5} \mathrm{c}^{-1}\right.$ в 93,6\% $\mathrm{H}_{2} \mathrm{SO}_{4}$ при $\left.363 \mathrm{~K}^{[44]}\right)$ не только по сравнению с $\mathrm{Fe}^{\mathrm{III}}$-порфиринами, ${ }^{[47,48]}$ но и по сравнению с комплексом $\mathrm{Fe}^{\mathrm{III}}$-фталоцианина. ${ }^{[1, \text { стр. 139] }}$

Сильное взаимодействие между $\pi$-орбиталями макроцикла и частично заполненными $d$-орбиталями атома железа $(S=3 / 2)$ в пентакоординационных комплексах $\mathrm{Fe}^{\mathrm{III}}$-октафенилтетраазапорфина [(X)Fe $\left.{ }^{\mathrm{III}} \mathrm{OPTAP}\right]$ обуславливает очень необычный и характерный вид их ЭСП (см. Рисунок 5). Вместо двух интенсивных $Q$ - и $B$ - полос в видимой области ЭСП, типичных для низкоспиновых комплексов $\mathrm{Fe}^{\mathrm{II}}$ и $\mathrm{Fe}^{\mathrm{III}}$ в спектрах $[(\mathrm{X})$ $\mathrm{Fe}^{\mathrm{III}} \mathrm{OPTAP]} \mathrm{наблюдаются} \mathrm{четыре} \mathrm{полосы} \mathrm{с} \mathrm{убывающей}$ интенсивностью $(\lg \varepsilon=4,6 \rightarrow 3,9)$. Такой характер спектра связан с проявлением в ЭСП, наряду полосами $\pi \rightarrow \pi *$ переходов ( $Q$ при 530-560 нм и Сорэ при 310-330 нм), гипсохромно смещенными из-за дестабилизации низшей $\pi^{*}$-МО макроцикла при взаимодействии $\mathrm{c} d_{\pi}$ орбиталями, интенсивных полос переноса заряда с высших занятых $\pi$-МО ОРТАР на частично заполненные $d$-орбитали атома железа $\pi \rightarrow d_{\mathrm{z}^{2}}$ при 400 - 450 нм и $\pi \rightarrow d_{\pi}$ при 650 - 725 нм. Кроме того, согласно теоретическим работам, ${ }^{[49,50]}$ вследствие смешения квартетных состояний $\mathrm{Fe}^{\mathrm{III}}(S=3 / 2)$ с возбужденными синглетными и триплетными состояниями макроциклического лиганда в видимой области ЭСП может проявиться серия разрешенных триплет-квартетных переходов, а полосы

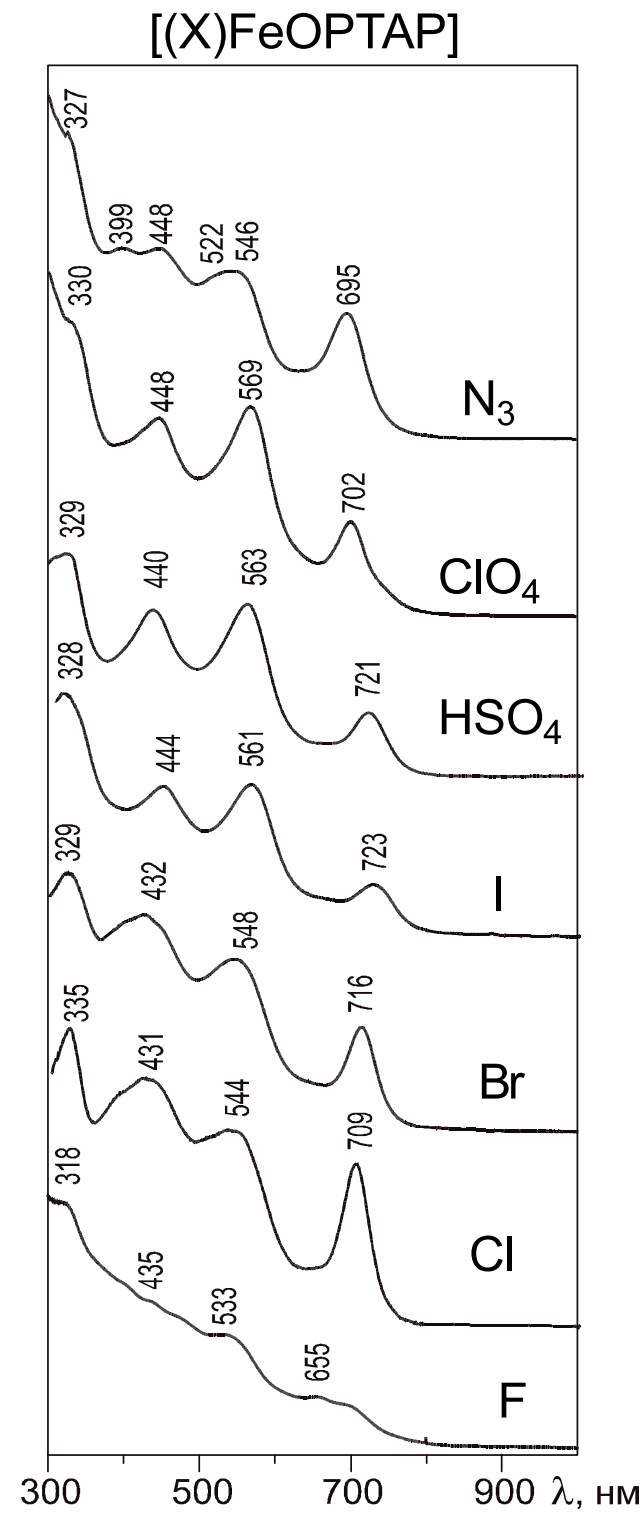

Рисунок 5. ЭСП пентакоординационных ацидокомплексов $\mathrm{Fe}^{\mathrm{III}}$-октафенилтетраазапорфина [(X)FeOPTAP] (X=F, Cl, Br, I, $\mathrm{HSO}_{4}, \mathrm{ClO}_{4}, \mathrm{~N}_{3}$ ) в $\mathrm{CH}_{2} \mathrm{Cl}_{2}$.

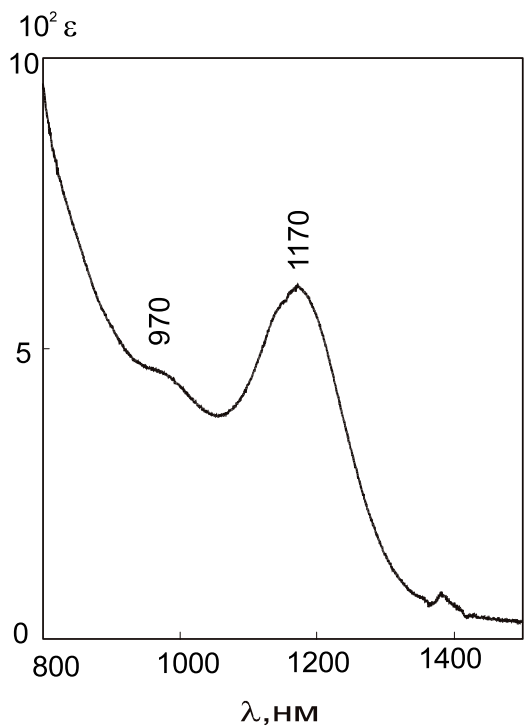

Рисунок 6. Ближняя ИК-область ЭСП [(Br)FeOPTAР] в $\mathrm{CH}_{2} \mathrm{Cl}_{2}$. 
слабой интенсивности, наблюдаемые в ближней ИКобласти (см. Рисунок 6) можно отнести к переходам между $3 d$ орбиталями $\mathrm{Fe}^{\mathrm{III}}: d_{\mathrm{xy}} \rightarrow d_{\pi}(1100-1200 \mathrm{Hм}, \lg \varepsilon \approx$ $2,5-3)$ и $d_{\mathrm{z} 2} \rightarrow d_{\mathrm{x} 2-\mathrm{y} 2}(950-1000$ нм, $\lg \varepsilon \approx 2)$.

Электрохимические исследования (Таблица 4) показали, что в пентакоординационных комплексах $\mathrm{Fe}^{\mathrm{III}}$-октафенилтетраазапорфина $\left[(\mathrm{X}) \mathrm{Fe}^{\mathrm{III}} \mathrm{OPTAP}\right]$ восстановление $\mathrm{Fe}^{\mathrm{III}} / \mathrm{Fe}^{\mathrm{II}}$ проходит гораздо легче, чем в соответствующих комплексах $\mathrm{Fe}^{\mathrm{III}}$-порфиринов (например, +0.02 для $\left[(\mathrm{Cl}) \mathrm{Fe}^{\mathrm{III}} \mathrm{OPTAP}\right]$ и $-0,52$ В для $[(\mathrm{Cl})$ $\left.\mathrm{FeOEP}]^{[43]}\right)$. Очень легко при $-0,3--0,4$ В протекает и процесс дальнейшего восстановления металла $\mathrm{Fe}^{\text {II }}$ $\mathrm{Fe}^{\mathrm{I}}$, что отличает пентакоординационные ацидокомплексы $\left[(\mathrm{X}) \mathrm{Fe}^{\mathrm{III}} \mathrm{OPTAP}\right]$ от гексакоординационных низкоспиновых комплексов $\mathrm{Fe}^{\mathrm{II}}$ и $\mathrm{Fe}^{\mathrm{III}}\left[(\mathrm{L})_{2} \mathrm{Fe}^{\mathrm{II}} \mathrm{OPTAP}\right]$ и $\left[(\mathrm{L})_{2} \mathrm{Fe}^{\mathrm{III} O P T A P}\right]^{+}$. Восстановление $\mathrm{Fe}^{\mathrm{II}} / \mathrm{Fe}^{\mathrm{I}}$ и образование $\pi$-анион-радикальной формы происходит при менее отрицательных потенциалах, чем для комплексов железа с порфиринами и фталоцианином. ${ }^{[42]}$ Усиление $\pi$-акцепторных свойств порфиринового макроцикла при мезо-тетраазазамещении определяет и высокий окислительный потенциал самого макроцикла. Поэтому, в отличие от $\mathrm{Fe}^{\mathrm{III}}$-порфиринов и $\mathrm{Fe}^{\mathrm{III}}$-фталоцианинов, даже при действии таких сильных окислителей как галогены или $100 \%$-ная $\mathrm{HNO}_{3}$ не образуется $\pi$-катион радикальной формы $\mathrm{Fe}^{\mathrm{III}}$-октафенилтетраазапорфиринов.

\section{Гексакоординационные комплексы $\mathrm{Fe}^{I I I}(S=1 / 2)$}

Координационная ненасыщенность центрального атома металла в пентакоординационных ацидокомплексах [(X)FeOPTAP] обуславливает их высокую реакционную способность в реакциях экстракоординации. В присутствии нуклеофилов (N-основания, гидроксид, алкоксид, псевдогалогениды, фторид) происходит практически мгновенное присоединение экстралиганда в транс-положение с образованием гексакоординационных комплексов $\mathrm{Fe}^{\mathrm{III}}$ - [(L)(X)Fe ${ }^{\mathrm{III} O P T A P], ~}$ $\left[(\mathrm{A})(\mathrm{X}) \mathrm{Fe}^{\mathrm{III}} \mathrm{OPTAP}\right]^{-}$(Рисунок 7), сопровождающееся более медленной стадией замещения ацидолиганда $\mathrm{X}^{-} \mathrm{c}$ образованием катионных $\left[(\mathrm{L})_{2} \mathrm{Fe}^{\mathrm{III}} \mathrm{OPTAP}\right]^{+}$или анионных [(A) Fe $\left.^{\text {III OPTAP] }}\right]^{-}$комплексов. ${ }^{[31,34,51-53]}$

Следует отметить, низкоспиновые комплексы $\mathrm{Fe}^{\mathrm{III}}$ получаются в органических растворителях с низкой диэлектрической проницаемостью (углеводороды и их галогенпроизводные), а в таких растворителях как ацетон, диметалисульфоксид в присутствии избытка экстралиганда (N-основания, цианид-анион) очень легко происходит их дальнейшее восстанавление до низкоспиновых комплексов $\mathrm{Fe}^{\mathrm{II}}$ : [(L $\left.)_{2} \mathrm{Fe}^{\mathrm{II}} \mathrm{OPTAP}\right]$ или $\left[(\mathrm{A})_{2} \mathrm{Fe}^{\mathrm{II} O P T A P}\right]^{2-}$.

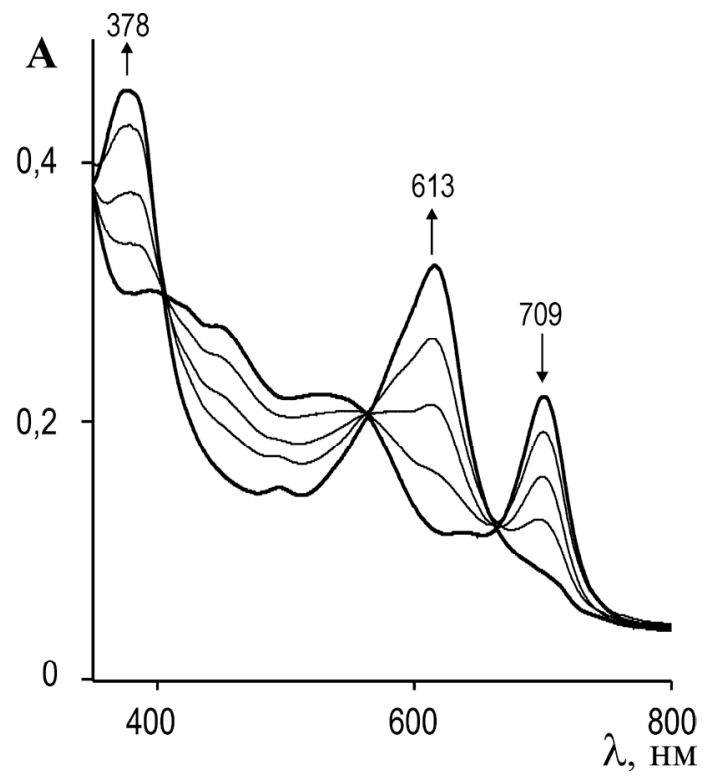

Рисунок 7. Изменение ЭСП раствора $[(\mathrm{Cl}) \mathrm{FeOPTAP}]$ в толуоле при образовании низкоспинового комплекса $[(1-\mathrm{MeIm})(\mathrm{Cl}) \mathrm{FeOPTAP}]$.

Механизм этой реакции до конца не ясен, однако, повидимому, восстановителем может служить $\mathrm{OH}^{-}$, образующийся в присутствии следов воды в растворителях.

Гексакоординационные комплексы $\mathrm{Fe}^{\mathrm{III}}$-октафенилтетраазапорфина являются низкоспиновыми. Это подтверждается данными по магнитной восприимчивости $\left(\mu_{э ф \phi}=1,5-2,0 \mu_{\mathrm{B}}\right)$, параметрами Мессбауэровских спектров $\left(\delta_{\mathrm{Fe}} 0,1-0,2 \mathrm{mм} / \mathrm{c}\right.$ и $\Delta E_{\mathrm{Q}} 2,1-2,3$ мм/с, Таблица 3$)$. В ПМР спектрах (Таблица 2) сигналы уширены и наблюдается сильнопольный изотропный сдвиг синалов протонов орто- и пара-положений фенильных колец (на 5 и 3 м.д.) за счет $\pi$-контактного механизма делокализации спиновой плотности с $d_{\pi}$ орбиталей, а вклад дипольного механизма невелик (для мета-протонов сильнопольный сдвиг всего 0,6 м.д.)

ЭПР спектры, измеренные для алкоксидных комплексов [(RO) 2 FeOPTAP]- (Таблица 5), ${ }^{[52]}$ имеют выраженный ромбический характер $\left(g_{\mathrm{x}}<g_{\mathrm{y}}<g_{\mathrm{z}}\right)$, причем величина ромбического расщепления $V / \lambda$ характерна для низкоспиновых $\mathrm{Fe}^{\mathrm{III}}$-порфиринов с основным состоянием $\left(d_{\mathrm{xy}}\right)^{2}\left(d_{\pi}\right)^{3}$. Параметр тетрагонального расщепления $\Delta / \lambda$ в $\left[(\mathrm{RO})_{2} \mathrm{FeOPTAP}^{-}\right.$существенно выше, чем в соответствующих комплексах $\mathrm{Fe}^{\mathrm{III}}$-порфиринов. ${ }^{[54]}$ Это является следствием усиления $\pi$-акцепторных свойств макроцикла при мезо-тетраазазамещении.

Отличительным признаком ЭСП гексакоординационных комплексов октафенилтетраазапорфина с

Таблица 5. Параметры ЭПР-спектров низкоспиновых алкоксидных комплексов Fe ${ }^{\mathrm{III}}$-октафенилтетраазапорфиринов в толуоле при $77 \mathrm{~K}^{[52]}$

\begin{tabular}{cccccc}
\hline Соединение & $g_{\mathrm{x}}$ & $g_{\mathrm{y}}$ & $g_{\mathrm{z}}$ & $V / \lambda$ & $\Delta / \lambda$ \\
\hline$\left[(\mathrm{BuO})_{2} \mathrm{FeOPTAP}^{-}\right.$ & 1,950 & 2,128 & 2,353 & 5,72 & 10,80 \\
{$\left[(\mathrm{AmO})_{2} \mathrm{FeOPTAP}^{-}\right.$} & 1,950 & 2,123 & 2,347 & 5,78 & 11,11 \\
{$\left[(\mathrm{PhO})_{2} \mathrm{FeOPTAP}^{-}\right.$} & 1,944 & 2,145 & 2,359 & 5,60 & 9,37 \\
{$\left[(\mathrm{MeO})_{2} \mathrm{FeTPP}^{-[54]}\right.$} & 1,914 & 2,165 & 2,494 & 4,14 & 8,28 \\
\hline
\end{tabular}




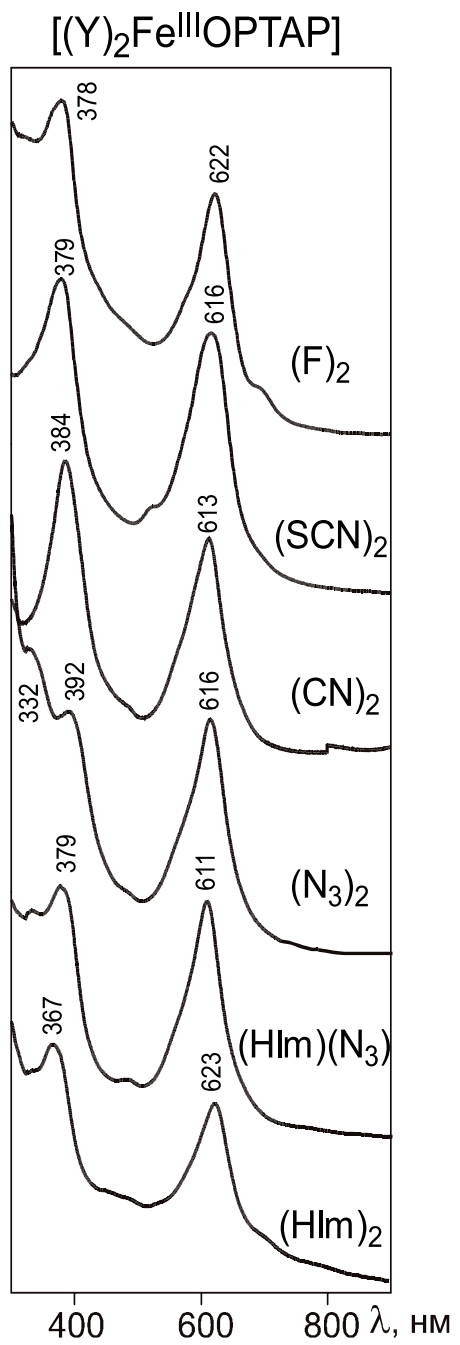

Рисунок 8. ЭСП низкоспиновых гексакоординационных комплексов $\mathrm{Fe}^{\mathrm{III}}$ октафенилтетраазапорфина [(А), $\mathrm{FeOPTAP]-}$ $\left(\mathrm{A}=\mathrm{F}, \mathrm{SCN}, \mathrm{CN}, \mathrm{N}_{3}\right),[(\mathrm{A})(\mathrm{L}) \mathrm{FeOPTAP}]\left(\mathrm{A}=\mathrm{N}_{3}, \mathrm{~L}=\mathrm{HIm}\right)$ и $\left[(\mathrm{L})_{2} \mathrm{FeOPTAP}\right]^{+}(\mathrm{L}=\mathrm{HIm})$ в $\mathrm{CH}_{2} \mathrm{Cl}_{2}$.

$\mathrm{Fe}^{\mathrm{III}}$ является наличие уширенной $Q$-полосы поглощения без выраженной колебательной структуры (Рисунок 8). В области 400-500 нм и 650-750 нм в ЭСП наблюдаются также слабые полосы переноса заряда.

Процессы превращения пентакоординационных комплексов $\mathrm{Fe}^{\mathrm{III}}$ в низкоспиновые гексакоординационные комплексы изучались спектрофотометрическим методом. ${ }^{[22,53]}$ Установлено, что при взаимодействии $\left[(\mathrm{X}) \mathrm{Fe}^{\mathrm{III}} \mathrm{OPTAP}\right] \mathrm{c} \mathrm{N}$-основаниями в толуольном растворе присоединяется один экстралиганд:

$$
\left[(\mathrm{X}) \mathrm{Fe}^{\mathrm{III} O P T A P}\right]+\mathrm{L} \leftrightarrows\left[(\mathrm{X})(\mathrm{L}) \mathrm{Fe}^{\mathrm{III} O P T A P}\right] \quad K_{э 1}
$$

$\mathrm{B}$ более полярном $\mathrm{CHCl}_{3}$ происходит дальнейшая реакция замещения ацидолиганда $\mathrm{X}^{-}$и образуется катионный комплекс:

$$
\left[(\mathrm{X})(\mathrm{L}) \mathrm{Fe}^{\mathrm{III}} \mathrm{OPTAP}\right]+\mathrm{L} \leftrightarrows\left[(\mathrm{L})_{2} \mathrm{Fe}^{\mathrm{III}} \mathrm{OPTAP}\right]^{+} \mathrm{X}^{-} \quad K_{92}
$$

При взаимодействии с RO- сразу же образуются анионные комплексы: ${ }^{[52]}$

$$
\left[(\mathrm{X}) \mathrm{Fe}^{\mathrm{III}} \mathrm{OPTAP}\right]+2 \mathrm{RO}^{-} \leftrightarrows\left[(\mathrm{RO})_{2} \mathrm{Fe}^{\mathrm{II}} \mathrm{OPTAP}\right]^{-}
$$

Таблица 6. Константы экстракоординации $\left(\lg K_{э 1}\right)$ для

\begin{tabular}{|c|c|c|c|c|}
\hline $\mathrm{X}$ & $\mathrm{L}$ & $\lg K_{31}$ & $\lg \beta$ & Раств. \\
\hline $\mathrm{ClO}_{4}$ & 1-MeIm & $3,71 \pm 0,08$ & & $\mathrm{PhMe}$ \\
\hline \multirow[t]{3}{*}{$\mathrm{Cl}$} & 1-MeIm & $3,33 \pm 0,08$ & & $\mathrm{PhMe}$ \\
\hline & $\mathrm{MeO}^{-}$ & & $3,92 \pm 0,06$ & $\mathrm{PhMe}$ \\
\hline & $\mathrm{PhO}^{-}$ & & $2,08 \pm 0,05$ & $\mathrm{PhMe}$ \\
\hline \multirow[t]{7}{*}{$\mathrm{Br}$} & $\mathrm{HIm}$ & & $6,80 \pm 0,05$ & $\mathrm{CHCl}_{3}$ \\
\hline & $3,4-\mathrm{Me}_{2} \mathrm{Py}$ & & $4,41 \pm 0,05$ & $\mathrm{CHCl}_{3}$ \\
\hline & 4-MePy & & $4,08 \pm 0,05$ & $\mathrm{CHCl}_{3}$ \\
\hline & Py & & $3,66 \pm 0,06$ & $\mathrm{CHCl}_{3}$ \\
\hline & 2-MePy & & $1,00 \pm 0,06$ & $\mathrm{CHCl}_{3}$ \\
\hline & $2,4,6-\mathrm{Me}_{3} \mathrm{Py}$ & & $0,59 \pm 0,06$ & $\mathrm{CHCl}_{3}$ \\
\hline & 2-ClPy & & $-1,10 \pm 0,04$ & $\mathrm{CHCl}_{3}$ \\
\hline
\end{tabular}
$\left[(\mathrm{X}) \mathrm{Fe}^{\mathrm{III}} \mathrm{OPTAP}\right]$ и устойчивость $(\lg \beta)$ низкоспиновых экстракомплексов $\left[(\mathrm{L})_{2} \mathrm{Fe}^{\mathrm{III}} \mathrm{OPTAP}\right]^{+}$и $\left[(\mathrm{RO})_{2} \mathrm{Fe}^{\mathrm{III}} \mathrm{OPTAP}\right]^{-}$при $298 \mathrm{~K}$

Константы равновесия реакции экстракоординации $K_{э 1}$ и константы устойчивости экстракомплексов $\beta=K_{э 1} K_{э 2}$ были определены спектрофотометрическим методом (Таблица 6). Увеличение $\sigma$-донорных свойств $\mathrm{N}$-оснований стабилизирует экстракомплексы.

\section{Металлоорганические комплексы}

При взаимодействии галогенидных комплексов [(Hal)Fe $\left.{ }^{\mathrm{III}} \mathrm{OPTAP}\right]$ с $\mathrm{Mg}-$ и Li-органическими соединениями образуются металлоорганические комплексы с $\sigma$-связью $\mathrm{Fe}-\mathrm{C} \quad\left[(\sigma-\mathrm{R}) \mathrm{Fe}^{\mathrm{III} O P T A P}\right] .^{[55]}$ $\mathrm{B}$ отличие от $\sigma$-R-комплексов $\mathrm{Fe}^{\mathrm{III}}$-порфиринов, устойчивых лишь в инертной атмосфере, комплексы $\mathrm{Fe}^{\mathrm{III}}$-октафенилтетраазапорфина, в особенности $\sigma$-арильные, достаточно стабильны на воздухе. Повышение прочности связи $\mathrm{Fe}-\mathrm{C}$ при мезо-азазамещении в порфириновом макроцикле связано, прежде всего, с

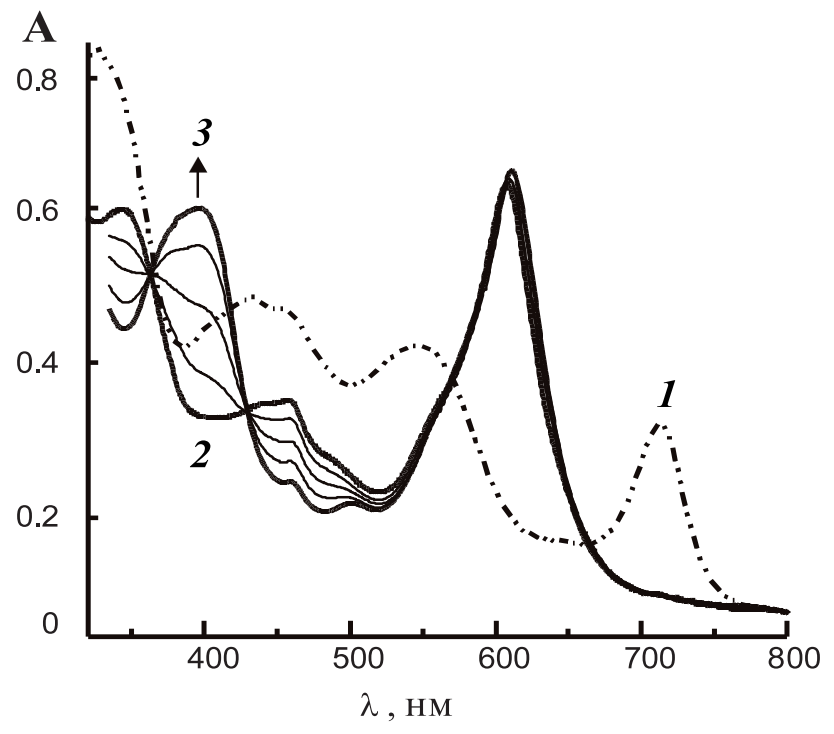

Рисунок 9. ЭСП толуольных растворов [(Cl)Fe $\left.\mathrm{F}^{\mathrm{III}} \mathrm{OPTAP}\right](1)$, $\left[(\mathrm{Ph}) \mathrm{Fe}^{\mathrm{III} \mathrm{OPTAP}]}(2)\right.$ и его изменение при экстракоординации 1-MeIm (3). 


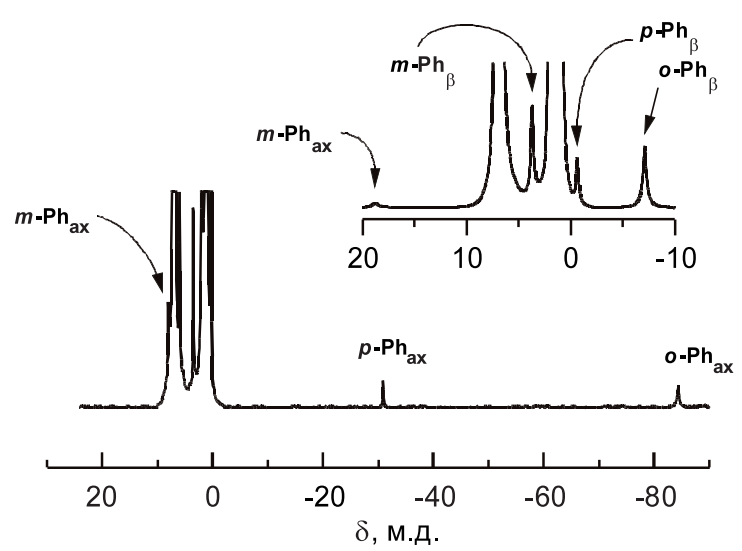

Рисунок 10. ${ }^{1} \mathrm{H}$ ЯМР спектр (300 МГц) [(Ph)Fe $\left.{ }^{I I I} \mathrm{OPTAP}\right]$ в толуоле- $d_{8}$ при $293 \mathrm{~K}$. На вставке показан фрагмент спектра при $180 \mathrm{~K}$

возрастанием $\pi$-акцепторных свойств макроциклического лиганда, приводящим к росту положительного заряда на атоме Fе и усилению $\sigma$-связывания $\mathrm{R} \rightarrow \mathrm{Fe}$, a в случае $\sigma$-арильных комплексов также $\pi$-связывания $\mathrm{Ar} \Rightarrow \mathrm{Fe}$. В отличие от галогенидных комплексов [( $\mathrm{Hal})$ $\left.\mathrm{Fe}^{\mathrm{III}} \mathrm{OPTAP}\right]$, органометаллические комплексы [( $\left.\sigma-\mathrm{R}\right)$ $\mathrm{Fe}^{\mathrm{III}} \mathrm{OPTAP]} \mathrm{являются} \mathrm{низкоспиновыми} \mathrm{соединения-}$ ми. Об этом свидетельствуют как характерные для перехода $S=3 / 2 \rightarrow 1 / 2$ изменения в ЭСП (Рисунок 9 , спектры 1 и 2), так и направление парамагнитных сдвигов протонов аксиальной и периферических фенильных групп в ПМР спектре [( $\left.\sigma-\mathrm{Ph}) \mathrm{Fe}^{\mathrm{III}} \mathrm{OPTAP}\right]$ (Рисунок 10$)$. Сильнейший сильнопольный сдвиг сигнала орто- и $n a p a$-протонов аксиальной $\sigma$-фенильной группы до -84 и -31 м.д., соответственно, указывает на делокализацию неспаренного электрона по контактному механизму за счет взаимодействия $d_{\pi} \Leftarrow \pi(\mathrm{Ph})$. Силь-

Таблица 7. Константы экстракоординации $\left(\lg K_{\mathrm{t}}\right) \mathrm{N}$-оснований $\sigma$-арильными комплексами $\mathrm{Fe}^{\mathrm{III}}$-октафенилтетраазапорфина в толуоле при $298 \mathrm{~K}$.

\begin{tabular}{|c|c|c|}
\hline [(Ar)Fe $\left.\mathrm{Fe}^{\mathrm{III} O P T A P}\right]$ & $\mathrm{L}$ & $\begin{array}{c}{\left[(\mathrm{Ar})(\mathrm{L}) \mathrm{Fe}^{\mathrm{III} \mathrm{OPTAP}}\right]} \\
\lg K_{\ni 1}\end{array}$ \\
\hline \multirow[t]{9}{*}{$\mathrm{Ar}=\mathrm{Ph}$} & Py & $2,10 \pm 0,15$ \\
\hline & 1-MeIm & $3,64 \pm 0,25$ \\
\hline & HIm & $3,34 \pm 0,28$ \\
\hline & 4-MePy & $2,53 \pm 0,06$ \\
\hline & 4-CNPy & $1,16 \pm 0,15$ \\
\hline & 3-ClPy & $1,25 \pm 0,10$ \\
\hline & 3-CNPy & $0,78 \pm 0,19$ \\
\hline & Pip & $2,94 \pm 0,30$ \\
\hline & $\mathrm{BzNH}_{2}$ & $2,14 \pm 0,06$ \\
\hline \multirow[t]{2}{*}{$\mathrm{Ar}=4-\mathrm{MePh}$} & Py & $1,97 \pm 0,13$ \\
\hline & 1-MeIm & $3,47 \pm 0,27$ \\
\hline \multirow[t]{2}{*}{$\mathrm{Ar}=4-\mathrm{MeOPh}$} & Py & $1,85 \pm 0,21$ \\
\hline & 1-MeIm & $3,28 \pm 0,17$ \\
\hline
\end{tabular}

нопольный сдвиг сигнала орто- и пара-протонов периферических $\beta$-фенильных групп меньше и наглядно проявляется при низкой температуре (Рисунок 10, вставка).

$\sigma$-Арильные комплексы [( $\left.\sigma-\mathrm{Ar}) \mathrm{Fe}^{\mathrm{III}} \mathrm{OPTAP}\right]$ взаимодействуют с $\mathrm{N}$-основаниями $\mathrm{L}$ с образованием гексакоординационных комплексов (Рисунок 9, спектры $2 \rightarrow 3)$ :

$\left[(\sigma-\mathrm{Ar}) \mathrm{Fe}^{\mathrm{III} O P T A P}\right]+\mathrm{L} \leftrightarrows\left[(\sigma-\mathrm{Ar})(\mathrm{L}) \mathrm{Fe}^{\mathrm{III} O P T A P}\right] \quad K_{\ni 1}$

Константы равновесия экстракоординации $K_{э}$ были определены ${ }^{[53,56]}$ спектрофотометрическим методом (Таблица 7). Установлено, что, хотя $\sigma$-эффект координации вносит основной вклад в связывание $\mathrm{N}$-основания, в случае пиридинов дополнительно наблюдается обратный, а в случае имидазолов - прямой дативный $\pi$-эффект координации. Увеличение $\sigma$-донорных свойств арильного аниона снижает устойчивость экстракомплексов с N-основаниями. Вместе с тем, следует отметить близкую устойчивость экстракомплексов с 1-MeIm, образуемых низкоспиновыми $\sigma$-арильными комплексами [( $\left.\sigma-\mathrm{ArFe}^{\mathrm{II}} \mathrm{OPTAP}\right]$ (Таблица $7, \lg K_{э 1}=3,3-$ $3,6)$ и промежуточноспиновыми ацидокомплексами $\left[(\mathrm{X}) \mathrm{Fe}^{\mathrm{II}} \mathrm{OPTAP}\right]$ (Таблица $6, \lg K_{э 1}=3,33$ и 3,74 для $\mathrm{X}=\mathrm{Cl}$ и $\mathrm{ClO}_{4}$, соответственно).

\section{Биядерные $\mu$-мостиковые комплексы}

Важными координационными формами Fe-октафенилтетраазапорфина являются впервые полученные нами биядерные $\mu$-комплексы $\left[\mu-\mathrm{X}\left(\mathrm{Fe}^{\mathrm{III}} \mathrm{OPTAP}\right)_{2}\right]$ (Схема 2), в которых два атома железа соединены одноатомным мостиком $\mathrm{X}=\mathrm{O}, \mathrm{N}, \mathrm{C}$ ( $\mu$-оксо-, $\mu$-нитридо, $\mu$-карбидокомплексы, часто называемые «димерами»). Их характерными спектральными особенностями являются проявление полосы несимметричных валентных колебаний мостикового фрагмента $v_{\text {as }}(\mathrm{FeXFe})$ в ИК-спектрах и уширение $Q$-полосы в ЭСП вследствие экситонного взаимодействия двух соседних $\pi$-хромофоров (Рисунок 11).

$\mu$-Оксокомплекс $\quad\left[\mu-O\left(\text { Fe }^{\mathrm{III}} \text { OPTAP }\right)_{2}\right]^{[30-32,44]}$ образуется при окислении комплексов $\mathrm{Fe}^{\mathrm{II}}$ на воздухе (Схема 1), а также из ацидокомплексов [(X)Fe $\left.{ }^{I I} \mathrm{OPTAP}\right]$ при пропускании их растворов через нейтральную или основную $\mathrm{Al}_{2} \mathrm{O}_{3}$ или при спонтанной дегидратации дигидроксокомплексов [(HO) $\left.{ }_{2} \mathrm{Fe}^{\mathrm{III}} \mathrm{OPTAP}\right]$, происходящей при их выделении из раствора (Схема 2). Параметры Мессбауэровского спектра $\mu$-оксокомплекса $\left[\mu-\mathrm{O}(\mathrm{FeOPTAP})_{2}\right]\left(\delta_{\mathrm{Fe}}=0,40\right.$ мм/с и $\Delta E_{\mathrm{Q}}=0,89$ $\mathrm{Mm} / \mathrm{c})$ типичны для комплексов $\mathrm{Fe}^{\mathrm{III}}$ в высокоспиновом состоянии $S=5 / 2$. Величина магнитного момента $\mu_{\text {эфф}}=2,42 \mu_{\mathrm{B}}$ свидетельствует о сильном антиферромагнитном взаимодействии двух парамагнитных центров.

Действие кислоты HX на $\left[\mu-\mathrm{O}\left(\mathrm{Fe}^{\mathrm{III}} \mathrm{OPTAP}\right)_{2}\right]$ приводит к образованию пентакоординационных моноядерных комплексов [(X)Fe $\left.{ }^{\mathrm{III} O P T A P}\right]$. При изучении кинетики диссоциации $\left[\mu-\mathrm{O}\left(\mathrm{Fe}^{\mathrm{III}} \mathrm{OPTAP}\right)_{2}\right]$ в среде бензол- $\mathrm{CH}_{3} \mathrm{COOH}$ было показано, что при мезотетраазазамещении устойчивость $\mu$-оксокомплексов 


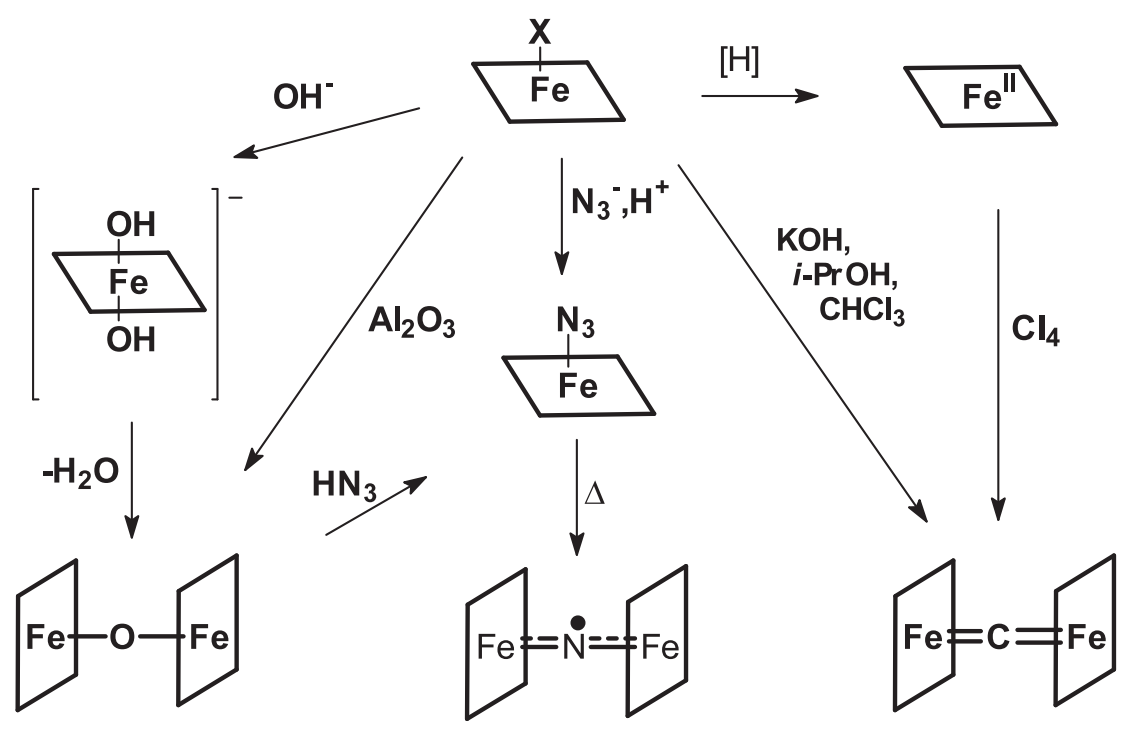

Схема 2. Синтез биядерных комплексов Fе-октафенилтетраазапорфина [ $\mu$-X(FeOPTAP) $)_{2}$.
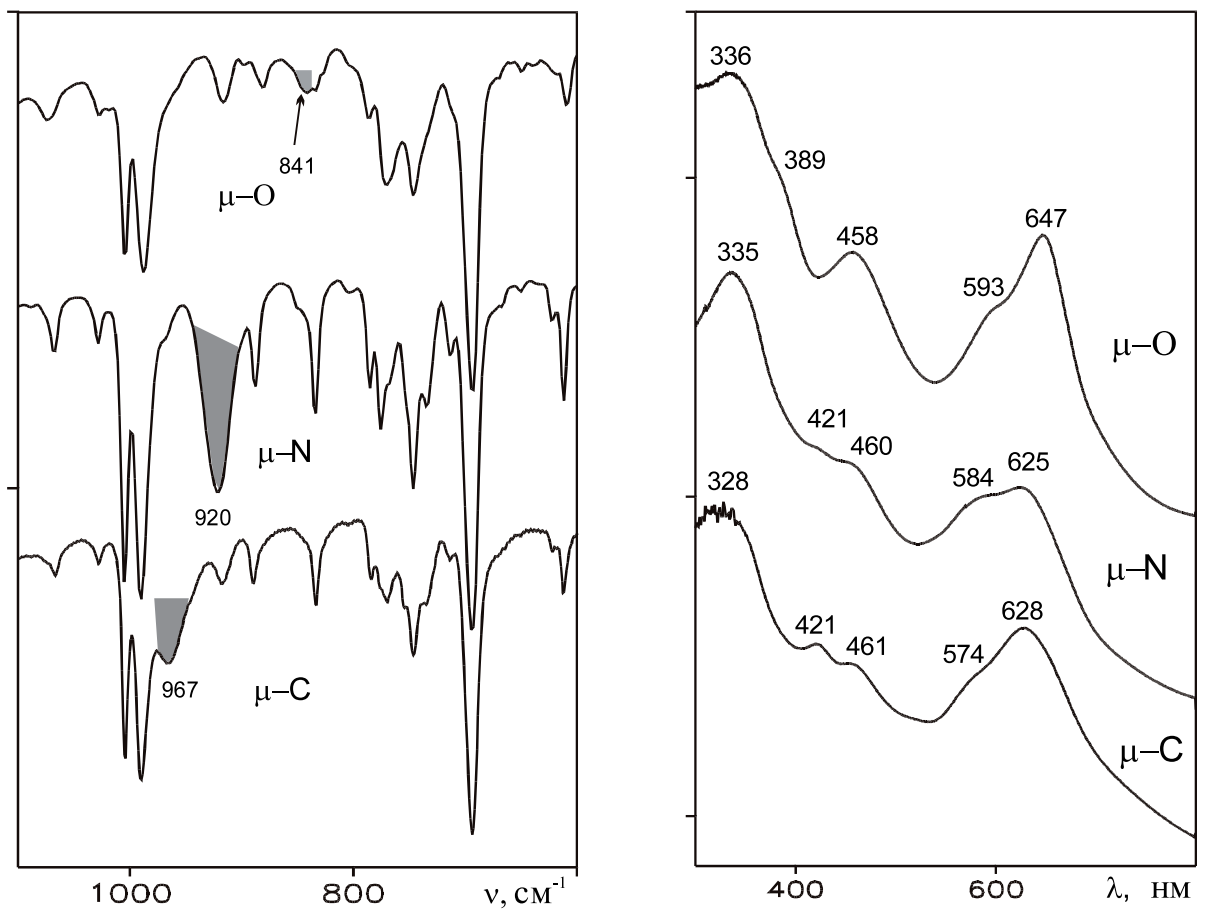

Рисунок 11. ИК и ЭСП биядерныХ комплексов Fе-октафенилтетраазапорфина [ $\left.\mu-\mathrm{X}\left(\mathrm{Fe}^{\mathrm{III}} \mathrm{OPTAP}\right)_{2}\right]$.

повышается. ${ }^{[4]}$ Это связано как со снижением основности $\mu$-оксо-мостика, так и со стерическими факторами.

При взаимодействии $\mu$-оксокомплексов с N-основаниями L на первой стадии происходит быстрая обратимая координация двух молекул L в транс-положение к $\mu$-оксомостику с образованием гексакоординационных биядерных комплексов:[32]

$$
\left.\left.\left[\mu-\mathrm{O}\left(\mathrm{Fe}^{\mathrm{III}} \mathrm{OPTAP}\right)\right)_{2}\right]+2 \mathrm{~L} \leftrightarrows\left[\mu-\mathrm{O}\left((\mathrm{L}) \mathrm{Fe}^{\mathrm{III}} \mathrm{OPTAP}\right)\right)_{2}\right]
$$

По мере роста основности N-основания термодинамическая устойчивость [

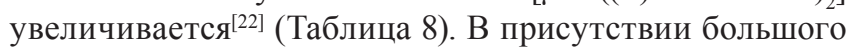
избытка L протекает медленная стадия расщепления $\mu$-оксомостика, сопровождающаяся восстановлением атома железа и образованием комплекса $\left[(\mathrm{L})_{2} \mathrm{Fe}^{\mathrm{II} O P T A P}\right]$.
Таблица 8. Константы устойчивости $(\lg \beta)$ аддуктов $\mu$-оксокомплекса $\mathrm{Fe}^{\mathrm{III}}$-октафенилтетраазапорфина с $\mathrm{N}$-основаниями в толуоле при 298 К.

\begin{tabular}{cc}
\hline $\mathrm{L}$ & $\lg \beta$ \\
\hline Py & $2,00 \pm 0,01$ \\
$4-\mathrm{MePy}$ & $2,59 \pm 0,06$ \\
HIm & $3,85 \pm 0,04$ \\
$1-\mathrm{MeIm}$ & $5,47 \pm 0,06$ \\
\hline
\end{tabular}

$\mu$-Нитридный комплекс $\left.[\mu \text {-N(FeOPTAP })_{2}\right]^{[29]}$ образуется при термолизе раствора азидного комплекса $\left[(\mathrm{N})_{3} \mathrm{FeOPTAP}\right]$ в кипящем бензоле или ксилоле. В ИКспектре $\left[\mu-\mathrm{N}(\mathrm{FeOPTAP})_{2}\right]$ проявляется характерная интенсивная полоса колебаний $v_{\mathrm{as}}(\mathrm{FeNFe})$ при 920 $\mathrm{cm}^{-1}$ (Рисунок 11). Параметры Мессбауэровского 


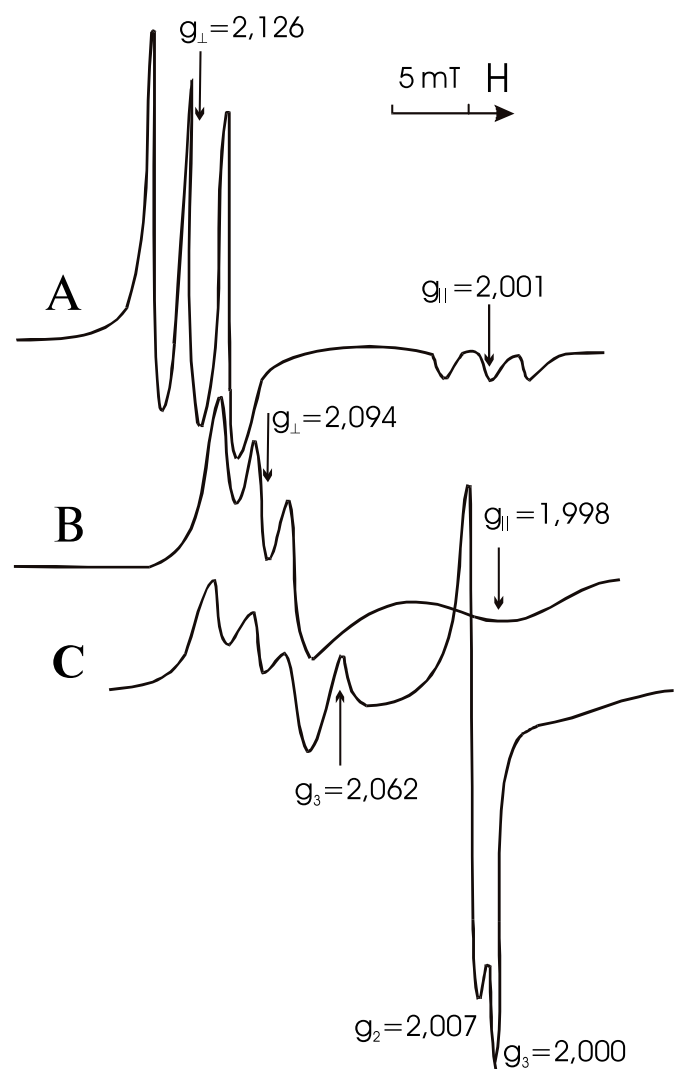

Рисунок 12. ЭПР спектры $\left[\mu-\mathrm{N}(\mathrm{FeOPTAP})_{2}\right]$ в толуоле (А) и в пиридине (Б,В). Б - в атм. $\mathrm{N}_{2}$, А и В - в присутствии $\mathrm{O}_{2}(77 \mathrm{~K})$.

спектра $\left(\delta_{\mathrm{Fe}}=-0,04 \mathrm{~mm} / \mathrm{c}\right.$ и $\Delta E_{\mathrm{Q}}=1,77 \mathrm{мм} / \mathrm{c}$, Таблица 3) свидетельствуют о том, что оба атома железа в составе этого биядерного комплекса эквивалентны и имеют

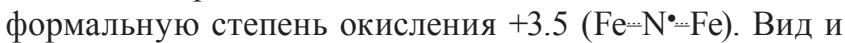
параметры ЭПР спектра [ $\left.\mu-\mathrm{N}(\text { FeOPTAР })_{2}\right]$ (Рисунок 12) показывают, что неспаренный электрон с $2 s$ орбитали $\mu$-нитридного атома азота делокализован преимущественно на $d_{z^{2}}$-орбиталях атомов Fe.

Методом ЭПР (Рисунок 12 В) было зафиксировано образование моноаддуктов $\left[\mu-\mathrm{N}(\mathrm{FeOPTAP})_{2}\right]$ с $\mathrm{N}$-основаниями L:

$$
\left[\mu-\mathrm{N}(\mathrm{FeOPTAP})_{2}\right]+\mathrm{L} \leftrightarrows\left[\mu-\mathrm{N}(\mathrm{FeOPTAP})_{2}\right](\mathrm{L})
$$

В результате координации L одним из атомов $\mathrm{Fe}$, неспаренный электрон смещается на $d_{z^{2}}$-орбиталь второго атома $\mathrm{Fe}$, благодаря чему у комплекса появляется способность обратимо связывать $\mathrm{O}_{2}$ за счет спаривания электронов $d_{\mathrm{z}^{2}}(\mathrm{Fe})-\pi^{*}\left(\mathrm{O}_{2}\right)$ :

$$
\left[\mu-\mathrm{N}(\mathrm{FeOPTAP})_{2}\right](\mathrm{L})+\mathrm{O}_{2} \leftrightarrows\left[\mu-\mathrm{N}(\mathrm{FeOPTAP})_{2}\right](\mathrm{L})\left(\mathrm{O}_{2}\right)
$$

Действие окислителей $\left(\mathrm{Br}_{2}, \quad 100 \% \mathrm{HNO}_{3}\right)$ на $\mu$-[N(FeOPTAP $\left.)_{2}\right]$ приводит к образованию окисленной формы $\left[\mu-\mathrm{N}^{+}(\mathrm{FeOPTAP})_{2}\right]$, содержащей атомы $\mathrm{Fe}^{\mathrm{IV}}$ с вакантными $d_{\mathrm{z}^{2}}$-орбиталями, которая при взаимодействии c N-основаниями и другими нуклеофилами легко дает бисаддукты [ $\left.\mu-\mathrm{N}^{+}((\mathrm{Nuc}) \mathrm{FeOPTAP})_{2}\right] .^{[23]}$

Интересными оказались результаты исследования механизма образования биядерных $\mu$-нитридных комплексов. ${ }^{[57]}$ В случае $\left[\mu-\mathrm{N}(\mathrm{FeOPTAP})_{2}\right]$ лимитирующей стадией является термолиз азидного комплекса и образование реакционноспособного неустойчивого интермедиата, вероятно, содержащего $\mathrm{Fe}^{\mathrm{V}}$ с концевой нитридной группой:

$$
\left[\left(\mathrm{N}_{3}\right) \mathrm{Fe}^{\mathrm{III}} \mathrm{OPTAP}\right] \stackrel{\Delta}{\longrightarrow}\left[: \mathrm{N} \equiv \mathrm{Fe}^{\mathrm{V}} \mathrm{OPTAP}\right]+\mathrm{N}_{2}
$$

$\mu$-Нитридный комплекс образуется далее в результате процесса неполного переноса нитридного атома азота к атому Fe в азидном комплексе:

$$
\begin{aligned}
& {\left[: \mathrm{N} \equiv \mathrm{Fe}^{\mathrm{v}} \mathrm{OPTAP}\right]+\left[\left(\mathrm{N}_{3}\right) \mathrm{Fe}^{\mathrm{III}} \mathrm{OPTAP}\right] \rightarrow} \\
& {\left[\mu-\mathrm{N}\left(\mathrm{Fe}^{\mathrm{Iv}} \text { OPTAP }\right)_{2}\right]\left(\mathrm{N}_{3}\right) \stackrel{\Delta}{\longrightarrow}\left[\mu-\mathrm{N}(\mathrm{FeOPTAP})_{2}\right]}
\end{aligned}
$$

В качестве электрофильного реагента в реакции неполного переноса атома азота могут быть использованы также галогенидные производные (в том числе и порфиринов), а нуклеофильного - устойчивые нитридные комплексы $\mathrm{Mn}^{\mathrm{V}}$. Это позволяет селективно получать гетеролептические и гетерометаллические $\mu$-нитридо комплексы: ${ }^{[58,59]}$

$$
\begin{aligned}
& \left.\left[: \mathrm{N} \equiv \mathrm{Fe}^{\mathrm{V}} \mathrm{OPTAP}\right]+\left[(\mathrm{Cl}) \mathrm{Fe}^{\mathrm{III}} \mathrm{TPP}\right] \stackrel{\Delta}{\underset{[\mu-\mathrm{N}}{\longrightarrow}(\mathrm{FeOPTAP})(\mathrm{FeTPP})}\right] \\
& {\left[: \mathrm{N} \equiv \mathrm{Mn}^{\mathrm{V}} \mathrm{OPTAP}\right]+\left[(\mathrm{Cl}) \mathrm{Fe}^{\mathrm{III} O P T A P}\right] \stackrel{\Delta}{\underset{\left[(\mu-\mathrm{MnNFe})(\mathrm{OPTAP})_{2}\right]}{\longrightarrow}}}
\end{aligned}
$$

Свойства макроциклического лиганда оказывают существенное влияние на реакционную способность комплексов в реакции переноса атома азота и определяют его полноту. ${ }^{[59,60]}$ мезо-Тетраазазамещение с одной стороны упрочняет связь $\mathrm{N} \equiv \mathrm{M}$ в [:N $\left.\equiv \mathrm{M}^{\mathrm{V}} \mathrm{OPTAP}\right]$, a c другой увеличивает электрофильность атома металла в $\left[(\mathrm{X}) \mathrm{M}^{\mathrm{II}} \mathrm{OPTAP}\right]$. Поэтому при взаимодействии $\left[: \mathrm{N} \equiv \mathrm{Mn}^{\mathrm{V}} \mathrm{TPP}\right]$ с $\left[(\mathrm{Cl}) \mathrm{Fe}^{\mathrm{III}} \mathrm{OPTAP}\right]$ образуется не только $[(\mathrm{TPP})(\mu-\mathrm{MnNFe})(\mathrm{OPTAP})], \quad$ но и значительные количества $\mu$-[N(FeOPTAP $\left.)_{2}\right]$ :

$$
\begin{aligned}
& {\left[: \mathrm{N} \equiv \mathrm{Mn}^{\mathrm{V}} \mathrm{TPP}\right]+\left[(\mathrm{Cl}) \mathrm{Fe}^{\mathrm{III}} \mathrm{OPTAP}\right] \stackrel{\Delta}{\longrightarrow} \underset{[(\mathrm{TPP})(\mu-\mathrm{MnNFe})(\mathrm{OPTAP})]}{\longrightarrow}} \\
& {[(\mathrm{TPP})(\mu-\mathrm{MnNFe})(\mathrm{OPTAP})] \stackrel{\Delta}{\longrightarrow}} \\
& {\left[(\mathrm{Cl}) \mathrm{Mn}^{\mathrm{III}} \mathrm{TPP}\right]+\left[: \mathrm{N} \equiv \mathrm{Fe}^{\mathrm{V}} \mathrm{OPTAP}\right]}
\end{aligned}
$$

$\mu$-Карбидный комплекс $\left[\mu-\mathrm{C}\left(\mathrm{Fe}^{\mathrm{IV}} \mathrm{OPTAP}\right)_{2}\right]^{[23]}$ образуется при взаимодействии комплексов $\mathrm{Fe}^{\mathrm{III}}$ с донором атома углерода, в качестве которого может быть использован либо $\mathrm{CI}_{4}$ в присутствии восстановителя, либо дихлоркарбен, образующийся in situ при добавлении $\mathrm{CHCl}_{3}$ к $\left[(\mathrm{X}) \mathrm{Fe}^{\mathrm{III}} \mathrm{OPTAP}\right]$ в спиртовом растворе щелочи (Схема 2). Валентные колебания $\mu$-карбидного мостика обнаруживаются как в ИК-спектре $\left(v_{\mathrm{as}}=967 \mathrm{~cm}^{-1}\right)$ (Рисунок 11), так и в резонансном Рамановском спектре $\left(v_{\mathrm{s}}=466 \mathrm{~cm}^{-1}\right)$.

\section{Выводы и перспективы}

Комплекс октафенилтетраазапорфина с железом образует несколько типов координационных форм, 
характеризующихся различным координационным числом, степенью окисления и спиновым состоянием атома железа. Устойчивой формой комплексов $\mathrm{Fe}^{\mathrm{II}}$ являются диамагнитные $(S=0)$ гексакоординационные комплексы с N- или C-координирующими лигандами или анионами $\left[(\mathrm{L})_{2} \mathrm{Fe}^{\mathrm{II} O P T A P}\right]$ и $\left[(\mathrm{A})_{2} \mathrm{Fe}^{\mathrm{II} O P T A P}\right]^{2-}$, в то время как тетракоординационный комплекс [Fe $\left.{ }^{\mathrm{II}} \mathrm{OPTAP}\right]$ со спиновым состоянием $S=1$ легко окисляется на воздухе. Гексакоординационные комплексы $\mathrm{Fe}^{\mathrm{III}}$

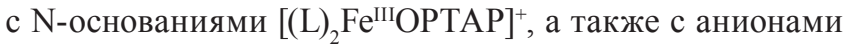

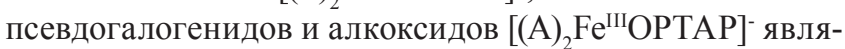
ются низкоспиновыми $(S=1 / 2)$, а пентакоординационные комплексы с анионами сильных минеральных

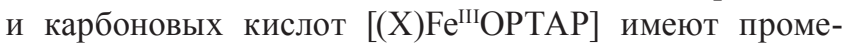
жуточное спиновое состояние $(S=3 / 2)$. Стабилизация низкоспиновых гексакоординационных комплексов $\mathrm{Fe}^{\mathrm{II}}$ и промежуточного спинового состояния в пентакоординационных ацидокомплексах $\mathrm{Fe}^{\mathrm{III}}$ является следствием мезо-тетраазазамещения, которое, уменьшая размеры координационной полости макроцикла, увеличивает его способность к б-связыванию и одновременно усиливает его $\pi$-акцепторные свойства. Важной координационной формой являются биядерные $\mu$-мостиковые комплексы: $\mu$-оксодимер $\mu$-[O(Fe $\left.\left.\mathrm{FI}_{\mathrm{II}} \mathrm{OPTAP}\right)_{2}\right]$, содержащий $\mathrm{Fe}^{\mathrm{III}}$ в высокоспиновом состоянии $(S=5 / 2)$, а также $\mu$-нитридодимер $\mu$-[N( $\left.\left.\mathrm{Fe}^{\mathrm{III} / 2 \mathrm{OPTAP}}\right)_{2}\right]$ и $\mu$-карбидодимер $\mu$-[C(Fe $\left.\left.{ }^{\mathrm{IV}} \mathrm{OPTAP}\right)_{2}\right]$, в которых стабилизируется высокое окислительное состояние атома железа. Изучены взаимные превращения координационных форм, однако механизм восстановления $\mathrm{Fe}^{\mathrm{III}}$ до $\mathrm{Fe}^{\mathrm{III}}$ под действием $\mathrm{N}$-оснований и других нуклеофилов остается неясным.

Перспективы дальнейших развития координационной химии комплексов железа с октафенилтетраазапорфином и другими тетраазапорфиринами связаны прежде всего с необходимостью систематического изучения процессов восстановления комплексов $\mathrm{Fe}^{\mathrm{III}}$ и $\mathrm{Fe}^{\mathrm{II}}$, а также с детальным исследованием биядерных $\mu$-нитридных и $\mu$-карбидных комплексов, в частности их каталитических свойств в реакциях окисления различных субстратов.

\section{Список литературы}

\section{References}

1. Berezin B.D. Koordinatsionnye soedineniya porfirinov $i$ ftalotsianina [Coordination compounds of porphyrins and phthalocyanine]. Moscow: Nauka, 1978. 280 p. (in Russ.)

2. Cook A.H., Linstead R.P. J. Chem. Soc. 1937, 929-933.

3. Berezin B.D., Khelevina O.G., Gerasimova N.D., Stuzhin P.A. Zh. Fiz. Khim. 1982, 56, 2768-2772 (in Russ). [Russ. J. Phys. Chem. 1982, 56(11), 1699-1702 (Engl).]

4. Linstead R.P., Whalley M. J. Chem. Soc. 1952, 4839-4846.

5. Ficken G.E., Linstead R.P. J. Chem. Soc. 1952, 4846-4854.

6. Berezin B.D., Khelevina O.G., Stuzhin P.A. Zh. Fiz. Khim. 1985, 59, 2181-2185 (Russ). [Russ. J. Phys. Chem. 1985, 59, 1295-1299 (Engl)].

7. (a) Stuzhin P.A., Khelevina O.G., Berezin B.D. Zh. Fiz. Khim. 1987, 61, 82-85 (in Russ). (b) Stuzhin P.A., Khelevina O.G., Berezin B.D. Koord. Khim. 1988, 14, 336-339 (in Russ).

8. Berezin B.D., Khelevina O.G., Stuzhin P.A., Glazunov A.V. Zh. Fiz. Khim. 1986, 60, 2189-2193 (Russ). [Russ. J. Phys.
Chem. 1986, 60, 1311-1314 (Engl)].

9. (a) Iodko S.S., Kaliya O.L., Lebedev O.L., Luk'yanets E.A. Koord. Khim., 1979, 5, 611 (in Russ). (b) Derkacheva V.M., Iodko S.S., Kaliya O.L., Luk'yanets E.A. Zh. Obshch. Khim., 1981, 51, 2319 (in Russ). (c) Iodko S.S., Kaliya O.L., Gal'pern M.G., Kopranenkov V.N., Lebedev O.L., Luk'yanets E.A. Koord. Khim., 1982, 8, 1025-1033 (in Russ). (d) Derkacheva V.M., Kaliya O.L., Luk'yanets E.A. Zh. Obshch. Khim., 1983, 53, 188-192 (in Russ). (e) Iodko S.S., Kaliya O.L., Kondratenko N.V., Luk'yanets E.A., Popov V.I., Yagupol'skii L.M. Zh. Obshch. Khim., 1983, 53, 901-903 (in Russ).

10. (a) Borovkov N.Y., Akopov A.S. Izv. Vyssh. Uchebn. Zaved., Khim. Khim. Tekhnol., 1985, 28(10), 34 (Russ). (b) Borovkov N.Y., Akopov A.S. Zh. Fiz. Khim. 1986, 60, 750-752 (in Russ). [Russ. J. Phys. Chem. 1986, 60, 448 (Engl)]. (c) Akopov A.S., Borovkov N.Y. Zh. Obshch. Khim., 1986, 56, 931-937 (in Russ). (d) Akopov A.S., Borovkov N.Y. Shchigal O.V. Koord. Khim., 1986, 12, 1051-1055 (in Russ). (e) Borovkov N.Y., Akopov A.S. Koord. Khim., 1987, 13, 1358-1361 (in Russ). (f) Akopov A.S., Borovkov N.Y. Koord. Khim., 1988, 14, 731-737 (in Russ). (g) Akopov A.S., Borovkov N.Y. Khim. Geterotsikl. Soedin., 1988, 1625-1630 (in Russ).

11. Ahrens U., Kuhn H. Z. Phys. Chem., Neue Folge, 1963, 37, 1.

12. (a) Gaspard S., Verdaquer M., Viovy R. J. Chim. Phys., 1972, 69, 1740. (b) Gaspard S., Verdaquer M., Viovy R. Comp. Rend. Acad. Sc. Paris, Ser. C, 1973, 277, 821. (c) Gaspard S., Verdaquer M., Viovy R. J. Chem. Research (M), 1979, 3072.

13. Stuzhin P.A., Khelevina O.G., Berezin B.D. Azaporphyrins: acid-base properties. In: Phthalocyanines: Properties and Applications. Volume 4. (Leznoff C.C. and Lever A.B.P., Edrs). New York: VCH Publishers, 1996, 19-79.

14. Stuzhin P.A. Synthesis, coordination and donor-acceptor properties of tetraazaporphine, its functional derivatives and their complexes. Diss. Cand. Chem. Sci. Ivanovo Institute of Chemical Technology, 1985, 216 p. (in Russ).

15. Lever A.B.P., Gray H.B. (Edrs). Iron Porphyrins. Part I. London: Addison-Wesley Publishing, 1983, 281 p. Part II. London: Addison-Wesley Publishing, 1983, 254 p. Part III. New York: VCH, 1989, $390 \mathrm{p}$.

16. Scheidt W.R., Reed C.A. Chem. Rev. 1981, 81, 543-555.

17. (a) Bundina N.I., Kaliya O.L., Lebedev O.L., Lukyanets E.A., Rodoinova G.N., Ivanova T.M. Koord. Khim. 1976, 2, 940947 (in Russ). (b) Bundina N.I., Gulina T.Y., Iodko S. S., Mekhryakova H.G., Kaliya O.L., Lukyanets E.A. Zh. Obshch. Khim. 1984, 54, 1199-1200 (in Russ). (c) Mekhryakova H.G., Bundina N.I., Gulina T.Y., Kaliya O.L., Lukyanets E.A. Zh. Obshch. Khim. 1984, 54, 1656-1660 (in Russ). (d) Nemykin V.N., Tretyakova I.N., Volkov S.V., Li V.D., Mekhryakova H.G., Kaliya O.L., Lukyanets E.A. Usp. Khim. 2000, 69, $355-$ 377 (in Russ).

18. (a) Ercolani C., Monacelli F., Rossi G. Inorg. Chem. 1979, 18, 712-716. (b) Ercolani C., Rossi G., Monacelli F. Inorg. Chim. Acta 1980, 44, L215-L216. (c) Ercolani C., Gardini M., Monacelli F., Pennesi G., Rossi G. Inorg. Chem. 1983, 22, 2584-2589. (d) Ercolani C., Gardini M., Murray K.S., Pennnesi G., Rossi G. Inorg. Chem. 1986, 25, 3972-3976. (e) Ercolani C., Gardini M., Murray K.S., Pennesi G., Rossi G., Zwack P.R. Inorg. Chem. 1987, 26, 3539-3543. (f) Ercolani C., Gardini M., Pennesi G., Rossi G. J. Mol. Catal. 1985, 30, 135-144.

19. (a) Kalz W., Homborg H. Z. Naturforsch. 1983, B38, 470-484. (b) Kalz W., Homborg H., Küppers H., Kennedy B.J., Murray K.S. Z. Naturforsch. 1984, B39, 1478-1489. (c) Kennedy B.J., Murray K.S., Zwack P.R., Homborg H., Kalz W. Inorg. Chem. 1985, 24, 3302-3305. (d) Küppers H., Kalz W., Homborg H. Acta Cryst. 1985, C41, 1420-1423. (e) Küppers H., Kalz W., Homborg H. Acta Cryst. 1986, C42, 925. (f) Küppers H., Eulert H.-H., Hesse H.-F., Kalz W., Homborg H. Z. Naturforsch. 1986, B41, 
44-47. (g) Kennedy B.J., Murray K.S., Zwack P.R., Homborg H., Kalz W. Inorg. Chem. 1986, 25, 2539-2545. (h) Sieversten S., Murray K.S., Moubaraki B., Berry K.J., Korbatieh Y., Cashion J.D., Brown L.J., Homborg H. Z. anorg. allg. Chem. 1994, 620, 1203-1212. (i) Potz R., Hückstädt H., Homborg H. Z. anorg. allg. Chem. 1998, 624, 173-174.

20. (a) Goedken V.L., Ercolani C. J. Chem. Soc. Chem. Comm. 1984, 6, 378-379. (b) Bottomley L.A., Gorce J.-N., Goedken V.L., Ercolani C. Inorg. Chem. 1985, 24, 3733-3737. (c) Ercolani C., Gardini M., Pennesi G., Rossi G., Russo U. Inorg. Chem. 1988, 27, 422-424.

21. Stuzhin P.A. Synthesis, structure and physical-chemical properties of azaporphyrins and porphyrazines. Diss. Dr. Chem. Sci. Ivanovo State University of Chemical Technology, 2004. 382 p. (in Russ).

22. Migalova I.S. Coordination properties of the Fe-complexes with aryl substituted porphyrins. Diss. Cand. Chem. Sci. Ivanovo State Academy of Chemical Technology, 1993. 140 p. (in Russ).

23. Hamdush M. Synthesis, study of structure and properties of $\mu$-dimers of Fe-porphyrins. Diss. Cand. Chem. Sci. Ivanovo State Academy of Chemical Technology, 1995. 183 p. (in Russ).

24. Mal'chugina O.V. Metalloorganic extracomplexes of porphyrazines. Diss. Cand. Chem. Sci. Ivanovo State University of Chemical Technology, 2001. 138 p. (in Russ).

25. Gromova T.V. Properties of porphyrins with chemically active NH-bond. Diss. Cand. Chem. Sci. Ivanovo Institute of Chemical Technology, 2000. 156 p. (in Russ).

26. Vagin S.I. Influence of coordinating metals $\mathrm{Fe}, \mathrm{Ru}$ and $\mathrm{Os}$ on the properties of tetraazaporphyrins, isocyanides, 5- and 6-membered nitrogen-containing heterocycles. Diss. Cand. Chem. Sci. Ivanovo State University of Chemical Technology, 2000. 153 p. (in Russ).

27. Fischer H., Endermann F. Ann. Chem. 1937, 531, 245-250.

28. Cook A.H. J. Chem. Soc. 1938, 1761-1780; 1845-1847.

29. Stuzhin P.A., Latos-Grazynski L., Jezierski A. Transition Met. Chem. 1989, 14, 341-346.

30. Stuzhin P.A., Migalova I.S., Berezin B.D. Zh. Neorg. Khim. 1993, 38, 2004-2010 (in Russ). [Russ. J. Inorg. Chem. 1993, 38, 1877-1883 (Engl).]

31. Stuzhin P.A., Hamdush M., Ziener U. Inorg. Chim. Acta 1995, 236, 131-139.

32. Stuzhin P.A., Migalova I.S., Berezin B.D. Zh. Neorg. Khim. 1998, 43, 1655-1660 (in Russ). [Russ. J. Inorg. Chem. 1998, 43, 1536-1541 (Engl).]

33. Vagin S.I., Stuzhin P.A., Hanack M. Zh. Obshch. Khim. 1999, 69, 319-324 (Russ). [Russ. J. Gen. Chem. 1999, 69, 308-313 (Engl.).]

34. Stuzhin P.A. Koord. Khim. 1995, 21, 125-131 (in Russ). [Russ. J. Coord. Chem. 1995, 21, 117-123 (Engl).]

35. Stuzhin P.A., Hückstädt H., Homborg H. In: IX International Conference on Chemistry of Porphyrins and their Analogues. 8-12 September 2003, Suzdal'. Proceedings. Ivanovo: ISUCT, 2003. P 63-65. Crystallographic data for $\mathrm{C}_{74} \mathrm{H}_{50} \mathrm{~N}_{10} \mathrm{Fe}, M=$ 1135.13, orthoromb., space group Cmca (№ 64), $a=23.5310$ (10) $\AA, b=12.307(3) \AA, c=19.552(3) \AA, V=5662.2(16) \AA^{3}, Z=$ $4, \rho_{\text {calc }}=1.384 \mathrm{~g} / \mathrm{cm}^{3}, T=170 \mathrm{~K}$, diffractometer Enraf-Nonius CAD- $4, \mathrm{MoK}_{\alpha}, \lambda=0.71073, \mu=0.327 \mathrm{~cm}^{-1}, F(000)=2450$, scan range $2.08^{\circ}<2 \theta<25^{\circ}$, number of reflections 2704 (independent - 2548), for $I>2 \sigma(I) R=0.0969, w R_{2}=0.2511$, GOF $=1.055$.

36. (a) Li N., Petricek V., Coppens P., Landrum J. Acta Cryst. C. 1985, 41, 902-905. (b) Li N., Coppens P., Landrum J. Inorg. Chem. 1988, 27, 482-488.
37. Stuzhin P.A., Migalova I.S., Homborg H. Koord. Khim. 2000, 26, 9-14. (in Russ). [Russ. J. Coord. Chem. 2000, 26, 6-11 (Engl)].

38. Mal'chugina O.V., Stuzhin P.A. Izv. Akad. Nauk, Ser. Khim. 2002, 2101-2106 (in Russ). [Russ. Chem. Bull. 2002, 51, 22612267 (Engl).]

39. Debrunner P.G. In: Iron Porphyrins, Part III. Lever A.B.P., Gray H.B. (Edrs) New York: VCH, 1989, 137-234.

40. Stuzhin P.A., Homborg H. Koord. Khim. 1997, 23, 666-671 (in Russ). [Russ. J. Coord. Chem. 1997, 23, 623-628 (Engl).]

41. Vinogradova T.V., Stuzhin P.A., Berezin B.D. In: I Intern. Conf. "Actual Problems of Chemistry and Chemical Technology” 15-25 September 1997. Ivanovo: ISACT, 1997. Section 2, 20-21 (in Russ).

42. Kadish K.M., Royal G., Van Caemelbecke E., Gueletti L. Metalloporphyrins in Non-aqueous media: Database of Redox Potentials. In: The Porphyrin Handbook (Kadish K.M., Smith K.M., Guilard R., Edrs). Amsterdam: Academic Press, 2000. Vol. 9, Ch. 59, 1-220.

43. Stolzenberg A.M., Strauss S.H., Holm R.H. J. Am. Chem. Soc. 1981, 103, 4763-4778.

44. Stuzhin P.A., Hamdush M., Berezin B. D. Zh. Fiz. Khim. 1996, 70, 807-814 (in Russ). [Russ. J. Phys. Chem. 1996, 70, 747-753 (Engl).]

45. Mitra S. In: Iron Porphyrins, Part II. (Lever A.B.P., Gray H.B., Edrs) London: Addison-Wesley Publishing Company, 1983, 1-42.

46. Hoff H.M. In: Iron Porphyrins, Part I. (Lever A.B.P., Gray H.B., Edrs) London: Addison-Wesley Publishing Company, 1983, 237-281.

47. Berezin B.D., Drobysheva A.N., Venediktov E.A. Koord. Khim. 1976, 2, 346-349. (in Russ).

48. Berezin B.D., Drobysheva A.N., Karmanova L.P. Koord. Khim. 1976, 2, 491-494. (in Russ).

49. Zerner M., Gouterman M., Kobayashi H. Theoret. Chim. Acta 1966, 6, 363-400.

50. Edwards W.D., Weiner B., Zerner M.C. J. Phys. Chem. 1988, 92, 6188-6197.

51. Stuzhin P.A., Khamdush M. Koord. Khim. 1998, 24, 330-335. (in Russ). [Russ. J. Coord. Chem. 1998, 24, 309-314. (Engl).]

52. Stuzhin P.A., Migalova I.S., Lipatov N.G., Berezin B.D. In: VII International Conference "The Problems of Solvation and Complex Formation in Solutions”. June 29 - July 2, 1998. Ivanovo, 1998, p. 263 (in Russ).

53. Stuzhin P.A., Mal'chugina, O.V., Kruchinina T.M., Migalova I.S., Berezin B.D. Koord. Khim. 1999, 25, 121-126 (in Russ). [Russ. J. Coord. Chem. 1999, 25, 113-117 (Engl).]

54. Otsuka T., Ohya T., Sato M. Inorg. Chem. 1985, 24, 776-782.

55. Stuzhin P.A., Mal'chugina O.V., Wolowiec S., Latos-Grazynski L., Berezin B.D. Mendeleev Commun. 1998, 143-145.

56. Mal'chugina O.V., Stuzhin P.A., Kruchinina T.M., Berezin B.D. Molecules 2001, 1505-1506.

57. Stuzhin P. A., Hamdush M. In: I International Conference on Biocoordination Chemistry. Ivanovo, 1994, p. 144.(in Russ).

58. Stuzhin P.A., Hamdush M., Homborg H. Mendeleev Commun. 1997, 196-198.

59. Galich L., Hückstädt H., Stuzhin P.A., Homborg H. In: $2^{\text {nd }}$ International Symposium on Phthalocyanines "Seventy years of Scientific Progress", September 21-23, 1998. Scotland, Pollock Halls: University of Edinbourgh, 1998, p. 60.

60. Stuzhin P.A., Fedotova E., Popkova I.A. In: VII International Conference "The Problems of Solvation and Complex Formation in Solutions". June 29 - July 2, 1998. Ivanovo, 1998, p. 316. (in Russ). 